\title{
Luminescent Cyclometalated Gold(III) Alkyl Complexes: Photophysical and Photochemical Properties
}

\author{
Wai-Pong To, ${ }^{\dagger}$ Glenna So Ming Tong, ${ }^{\dagger}$ Chi-Wah Cheung, ${ }^{\dagger}$ Chen Yang, ${ }^{\dagger}$ Dongling Zhou, ${ }^{\dagger}$ \\ and Chi-Ming Che ${ }^{*, \dagger, t}$
}

\begin{abstract}
${ }^{\dagger}$ State Key Laboratory of Synthetic Chemistry, Institute of Molecular Functional Materials, HKU-CAS Joint Laboratory on New Materials, Department of Chemistry, The University of Hong Kong, Pokfulam Road, Hong Kong, People's Republic of China

${ }^{\ddagger}$ HKU Shenzhen Institute of Research and Innovation, Shenzhen 518053, People’s Republic of China
\end{abstract}

\section{Supporting Information}

ABSTRACT: A series of luminescent cyclometalated gold(III) complexes having alkyls as auxiliary ligands has been prepared. The alkyl ligand was found to effectively increase the emission quantum yields and lifetimes of luminescent cyclometalated gold(III) complexes by circumventing the population of LLCT excited states that are found in complexes supported by arylacetylide ligands. These gold(III) alkyl complexes exhibit emission quantum yields and lifetimes of up to 0.40 and 180 $\mu \mathrm{s}$, respectively, in solution at room temperature. The triplet emission color of these complexes is tunable from yellow to sky blue by modifying the cyclometalating ligand.

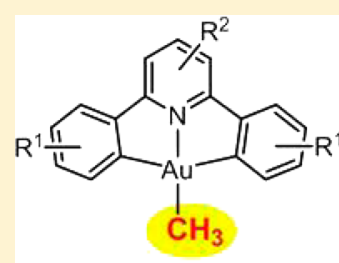

$\Phi$ up to $40 \%$ $\tau$ up to $180 \mu \mathrm{s}$

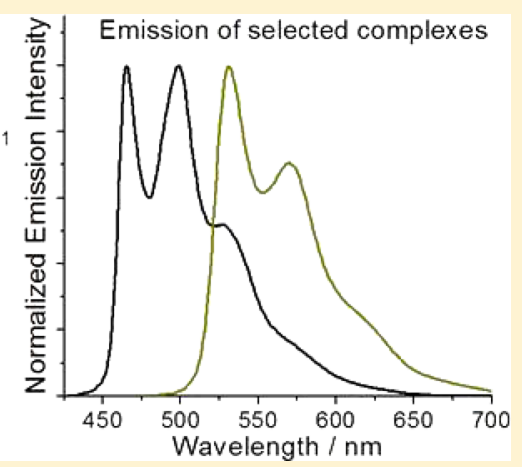

\section{INTRODUCTION}

In the development of phosphorescent gold(III) complexes, the use of strong $\sigma$-donating carbon donor ligand(s) for coordination is a common strategy used to achieve phosphorescence at room temperature. ${ }^{1}$ Coordination of a strong $\sigma$ donating ligand to gold(III) can raise the energy of the gold(III) $5 \mathrm{~d} \sigma^{*}\left(5 \mathrm{~d}_{x^{2}-y^{2}}\right)$ orbital, thus minimizing the thermal population of the nonemissive ${ }^{3} \mathrm{LMCT}$ (ligand-to-metal charge transfer) and ${ }^{3} \mathrm{dd}$ excited state. In the case of $\left[\mathrm{Au}\left(\mathrm{C}^{\wedge} \mathrm{N}^{\wedge} \mathrm{C}\right) \mathrm{C} \equiv\right.$ $\mathrm{CAr}]$, this would also increase the energy of the ${ }^{3} \mathrm{LLCT}$ (ligand-to-ligand charge transfer $)^{3}\left[\pi(\mathrm{C} \equiv \mathrm{CAr})-\pi^{*}\right.$ $\left.\left(\mathrm{C}^{\wedge} \mathrm{N}^{\wedge} \mathrm{C}\right)\right]$ ) excited state due to the destabilization of the LUMO on pyridine by the strong-field ligand. In the literature, most phosphorescent gold(III) complexes are constructed with a combination of a cyclometalating $\left[\mathrm{C}^{\wedge} \mathrm{N}\right]$ or $\left[\mathrm{C}^{\wedge} \mathrm{N}^{\wedge} \mathrm{C}\right]$ ligand (e.g., $\mathrm{HC}^{\wedge} \mathrm{N}=2$-phenylpyridine, $\mathrm{HC}^{\wedge} \mathrm{N}^{\wedge} \mathrm{CH}=2$,6-diphenylpyridine) together with auxiliary ligand $(s) .{ }^{2}$ The function of the cyclometalating ligand is to restrict the four-coordinated gold(III) complex in a planar coordination geometry from undergoing distortion, while the auxiliary ligands are employed to provide a strong ligand field so as to destabilize the gold(III) $5 \mathrm{~d}_{x^{2}-y^{2}}$ orbital. At present, the most commonly used auxiliary carbon donor ligands that can successfully switch on the emission of gold(III) complexes include acetylide, N-heterocyclic carbene (NHC), aryl, and cyanide. ${ }^{1}$ As the $\sigma$-donor strength of the ligand is crucial to effect luminescence, we conceive that alkyl ligands may be an appropriate choice in the construction of phosphorescent gold(III) complexes since (1) the $\mathrm{sp}^{3}$-hybridized carbon donor atom should provide a strong ligand field to destabilize the $5 \mathrm{~d}_{x^{2}-y^{2}}$ orbital and (2) there are no low-lying $\pi$ and $\pi^{*}$ orbitals of the alkyl ligand for forming a LLCT excited state that could complicate the excited state dynamics, which occurs in gold(III) complexes with arylacetylide ligands. ${ }^{2 j, 3}$ Herein we report the synthesis and photophysical properties of a series of cyclometalated gold(III) complexes with a doubly $\mathrm{C}$ deprotonated $\left[\mathrm{C}^{\wedge} \mathrm{N}^{\wedge} \mathrm{C}\right]$ chelating ligand and an alkyl group as the auxiliary ligand (Chart 1 ). These complexes exhibit strong ligand-centered phosphorescence in solution at room temperature with $E_{0-0}$ emission

Chart 1. Chemical Structures of Gold(III) Complexes in This Study
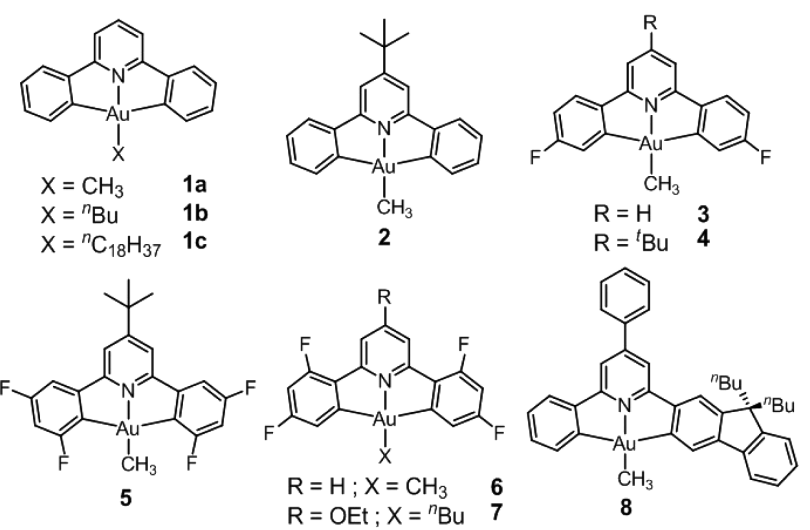

Received: January 20, 2017

Published: April 13, 2017 
energies as high as $2.80 \mathrm{eV}$ and quantum yields and lifetimes of up to 0.40 and $180 \mu \mathrm{s}$, respectively. The two structurally similar complexes $\left[\mathrm{Au}\left(\mathrm{C}^{\wedge} \mathrm{N}^{\wedge} \mathrm{C}\right) \mathrm{R}\right](\mathrm{R}=\mathrm{Me}, \mathrm{Et})$ have been reported by Bochmann and co-workers, but their photophysical properties have not been studied in detail. ${ }^{2 \mathrm{i}}$

\section{RESULTS}

Synthesis and Characterization. Cyclometalating $\left[\mathrm{C}^{\wedge} \mathrm{N}^{\wedge} \mathrm{C}\right]$ ligands were synthesized by a Kröhnke pyridine synthesis or Suzuki coupling similar to our previous work. ${ }^{2 j}$ Coordination of these ligands to gold(III) ions was achieved by transmetalation reactions between the mercury(II) chloride complexes bearing monodeprotonated $\left[\mathrm{HC}^{\wedge} \mathrm{N}^{\wedge} \mathrm{C}\right]$ ligands and $\mathrm{KAuCl}_{4}$ in refluxing $\mathrm{MeCN}^{2 j}$ The chloro ligand of the gold(III) complex was substituted with trifluoroacetate $\left(\mathrm{OCOCF}_{3}\right)$ by reaction with $\mathrm{AgOCOCF}_{3}$ in $\mathrm{CH}_{2} \mathrm{Cl}_{2} \cdot{ }^{2 \mathrm{~g}}$ Alkylation was accomplished by reaction of $\left[\mathrm{Au}\left(\mathrm{C}^{\wedge} \mathrm{N}^{\wedge} \mathrm{C}\right)\left(\mathrm{OCOCF}_{3}\right)\right]$ with alkyllithium (alkylmagnesium bromide for 1c) in THF at -78 ${ }^{\circ} \mathrm{C}$ and subsequent warming to room temperature. ${ }^{2 \mathrm{~h}}$ The products were purified by column chromatography on $\mathrm{SiO}_{2}$, and characterized by ${ }^{1} \mathrm{H} \mathrm{NMR},{ }^{13} \mathrm{C} \mathrm{NMR}$, mass spectrometry, and elemental analysis. The complexes are stable to air and moisture.

Diffraction-quality crystals of $\mathbf{1 a}$ and $\mathbf{4}$ were obtained by slow evaporation of $\mathrm{THF} /$ hexane solutions of the respective complex at room temperature. Perspective views of $1 \mathrm{a}$ and 4 are depicted in Figure 1. Selected bond lengths and angles are
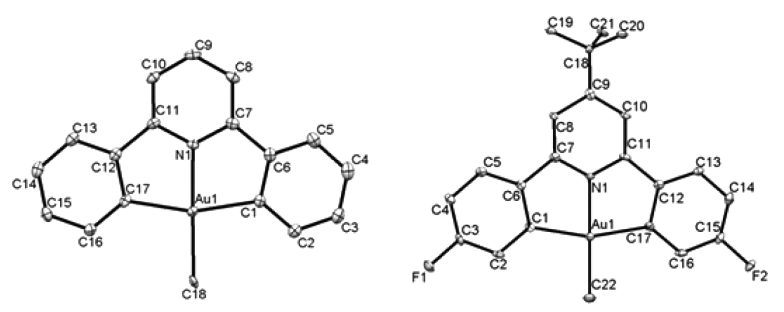

Figure 1. Perspective views of 1 a (left) and 4 (right). Hydrogen atoms are not shown.

summarized in Table $S 1$ in the Supporting Information. Coordination of the tridentate cyclometalating $\left[\mathrm{C}^{\wedge} \mathrm{N}^{\wedge} \mathrm{C}\right]$ ligand to the gold atom in both 1a and 4 leads to a distorted-squareplanar geometry with $\mathrm{C}\left(\mathrm{sp}^{2}\right)-\mathrm{Au}-\mathrm{C}\left(\mathrm{sp}^{2}\right)$ angles in the range of $161.6(4)-162.0(2)^{\circ}$. The $\mathrm{N}, \mathrm{Au}$, and $\mathrm{C}\left(\mathrm{sp}^{3}\right)$ atoms are almost collinear, with $\mathrm{N}-\mathrm{Au}-\mathrm{C}\left(\mathrm{sp}^{3}\right)$ angles of $178.5-178.65^{\circ}$. The $\mathrm{Au}-\mathrm{C}\left(\mathrm{sp}^{2}\right)$ distances are in the range of $2.050(8)-$ 2.076(5) $\AA$, whereas the $\mathrm{Au}-\mathrm{C}\left(\mathrm{sp}^{3}\right)$ distances vary from 2.051(12) to 2.121(5) $\AA$, both of which are similar to those of structurally comparable complexes. ${ }^{2 \mathrm{i}}$ The $\left[\mathrm{Au}\left(\mathrm{C}^{\wedge} \mathrm{N}^{\wedge} \mathrm{C}\right)\right]$ moieties are essentially planar. The closest interplanar distances between two $\left[\mathrm{Au}\left(\mathrm{C}^{\wedge} \mathrm{N}^{\wedge} \mathrm{C}\right)\right]$ planes are $3.397 \AA$ for $\mathbf{1 a}$ and $3.382 \AA$ for 4 , and the closest $\mathrm{Au}-\mathrm{Au}$ distances between two adjacent molecules of $1 \mathrm{a}$ and 4 are 5.271 and $5.036 \AA$, respectively.

For the gold(III)-methyl complexes studied herein, the ${ }^{1} \mathrm{H}$ NMR signal of the $\mathrm{Au}-\mathrm{CH}_{3}$ group appears as a sharp singlet lying between 1.21 and 1.40 ppm; complex 5 is an exception, in which the signal is a triplet and is more downfield at $1.86 \mathrm{ppm}$. The ${ }^{13} \mathrm{C}$ NMR signal of the methyl group ranges from 1.21 to 2.0 ppm.

Electron Microscopy. Morphology studies of gold(III) complexes are relatively sparse in the literature. ${ }^{4}$ The reported
SEM and TEM images of most gold(III) complexes show entangled fibrous structures on the order of micrometers. ${ }^{4 \mathrm{~b}-\mathrm{e}}$ Given the small size of the alkyl ligand, the use of the ligand may allow intermolecular dispersive and/or $\pi-\pi$ interactions which induce the formation of nanostructures. The morphologies of the nanostructures obtained with $1 \mathrm{1a}, 1 \mathrm{c}, 4$, and 5 in $\mathrm{THF} /$ hexane (v/v 1/9) mixture were therefore examined (Figure $2 \mathrm{a}-\mathrm{d}$ ). Interestingly, rectangular blocks, a fibrous

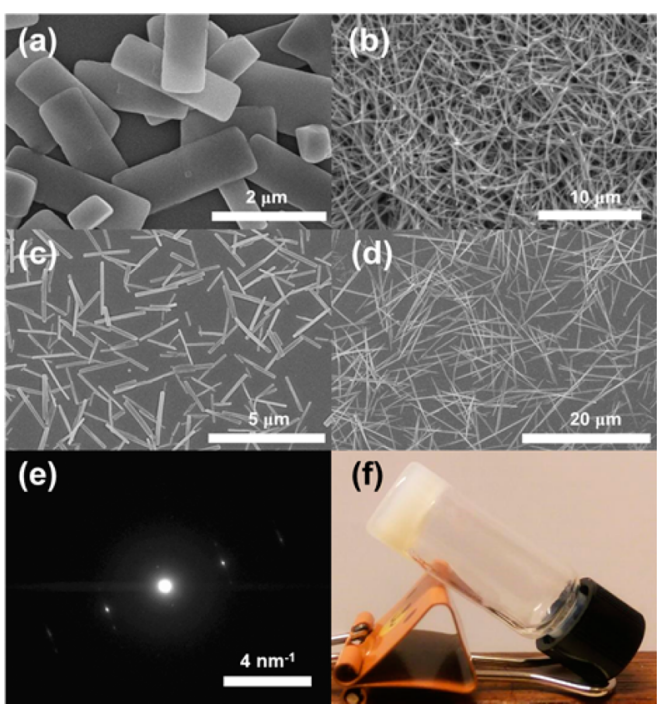

Figure 2. $(a-d)$ SEM images of nanostructures obtained from 1a, 1c, 4 , and 5 , respectively, in THF/hexane (v/v 1/9). (e) SAED pattern of nanowire formed from 5. (f) Photograph showing the gel of $1 \mathrm{c}(0.8 \mathrm{wt}$ $\%)$ in DMSO in a tilted vial.

network, rods, and wires were observed for 1a,c, 4, and 5, respectively. The dimensions of these structures ranged from $100 \mathrm{~nm}$ to $15 \mu \mathrm{m}$. Selected area electron diffraction (SAED) experiments revealed a crystalline nature of these structures. For example, the SAED pattern of nanowires of 5 (Figure 2e) showed a regular $d$ spacing of $3.58 \AA$ characteristic of $\pi-\pi$ interactions along the rod longitude. The gelation properties of these complexes were also tested. Only $1 \mathrm{c}$ was found to form an opaque, white gel upon cooling a hot DMSO solution of the complex $(0.8 \mathrm{wt} \%)$ to room temperature (Figure $2 \mathrm{f})$. Gelation was not observed for $\mathbf{1 c}$ in other solvents. Variable-temperature ${ }^{1} \mathrm{H}$ NMR spectra of $1 \mathrm{c}$ in $\mathrm{D}_{6}$-DMSO (Figure 3) revealed an upfield shift for $\mathrm{H}^{2}$ and downfield shifts for $\mathrm{H}^{1}, \mathrm{H}^{3}$, and $\mathrm{H}^{6}$,

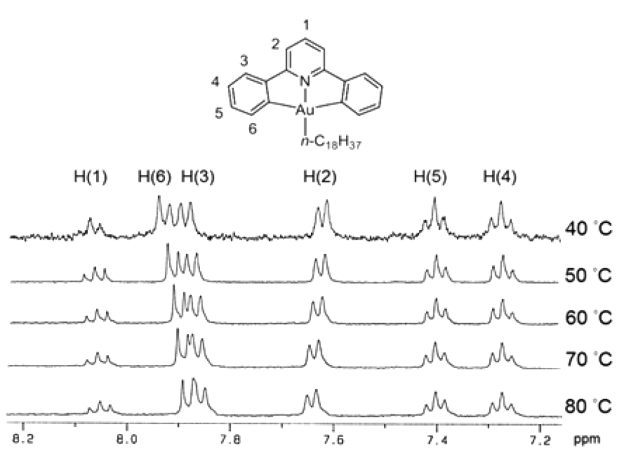

Figure 3. Variable-temperature ${ }^{1} \mathrm{H}$ NMR spectra showing the aromatic protons of $1 \mathrm{c}$ in $\mathrm{D}_{6}$-DMSO $\left(400 \mathrm{MHz},[\mathbf{1 c}]=2 \times 10^{-3} \mathrm{M}\right)$. No NMR signal of $1 \mathrm{c}$ was recorded at $25{ }^{\circ} \mathrm{C}$ due to low solubility. 
Table 1. Photophysical and Electrochemical Data of Gold(III) Complexes

\begin{tabular}{|c|c|c|c|c|}
\hline \multirow[b]{2}{*}{ complex } & \multirow[b]{2}{*}{ UV-vis absorption $\lambda_{\max }(\mathrm{nm})\left(\varepsilon\left(10^{3} \mathrm{dm}^{3} \mathrm{~mol}^{-1} \mathrm{~cm}^{-1}\right)\right)^{a}$} & \multicolumn{2}{|l|}{ emission } & \multirow{2}{*}{$\begin{array}{l}\text { reduction } \\
E_{\mathrm{pc}}(\mathrm{V})^{c}\end{array}$} \\
\hline & & $\lambda_{\max }(\mathrm{nm})(\tau(\mu \mathrm{s}))^{a}$ & $\Phi^{a, b}$ & \\
\hline $1 \mathbf{a}$ & 260 (sh, 24.6), 280 (14.1), 308 (9.3), 317 (10.0), 354 (3.2), 370 (3.8), 389 (3.1) & $465,498,530(43)$ & 0.11 & -2.16 \\
\hline $\mathbf{1 b}$ & 259 (sh, 26.7), 280 (15.0), 307 (10.0), 317 (10.7), 352 (3.2), 369 (3.7), $387(3.0)$ & $465,499,526(31)$ & 0.09 & -2.22 \\
\hline $1 c$ & 259 (sh, 22.8$), 280$ (12.5), 307 (8.3), 317 (9.0), 353 (2.7), 370 (3.1), 387 (2.5) & $465,498,526(39)$ & 0.09 & -2.20 \\
\hline 2 & 260 (sh, 25.3), 279 (13.0), 306 (8.9), 316 (9.7), 349 (2.9), 365 (3.4), 383 (2.8) & $464,497,530(40)$ & 0.10 & -2.32 \\
\hline 4 & 252 (sh, 41.0), $302(7.7), 312$ (9.2), 352 (2.7), 367 (3.8), 384 (3.3) & $462,494,523(38)$ & 0.10 & -2.28 \\
\hline 5 & $\begin{array}{l}260 \text { (sh, 20.1), } 274 \text { (sh, 15.0), } 283 \text { (sh, 13.0), } 310 \text { (12.0), } 323 \text { (11.6), } 340 \text { (sh, 3.7), } 358 \text { (3.9), } \\
\quad 376(2.9)\end{array}$ & $464,499,528(45)$ & 0.11 & -2.07 \\
\hline 6 & 274 (10.3), 282 (sh, 9.9), 310 (sh, 3.0), 334 (sh, 1.5), 352 (2.3), 368 (3.5), 385 (3.1) & $455,485,517(56)$ & 0.14 & -2.10 \\
\hline 7 & 258 (sh, 43.8), 286 (sh, 7.9), 294 (sh, 6.8), 302 (sh, 5.2), 318 (sh, 2.7), 332 (3.2), 347 (4.0), 364 (3.2) & $443,472,504(7)$ & 0.02 & -2.31 \\
\hline 8 & 276 (48.1), 299 (sh, 31.0), 320 (br, 26.3), 332(sh, 24.5), 348 (23.0), 377 (sh, 6.7), 398 (9.3), & $531,570,618(180)$ & 0.40 & -2.04 \\
\hline
\end{tabular}

${ }^{a}$ Determined in a degassed $\mathrm{CH}_{2} \mathrm{Cl}_{2}$ solution at $2 \times 10^{-5} \mathrm{M}$. ${ }^{b}$ Emission quantum yield $(\Phi)$ was estimated with BPEA (9,10bis(phenylethynyl)anthracene) in benzene as the standard $(\Phi=0.85) .{ }^{c}$ Measured in $\mathrm{CH}_{2} \mathrm{Cl}_{2}$ under argon with $0.1 \mathrm{M}$ tetra- $n$-butylammonium hexafluorophosphate as the supporting electrolyte; values versus $\mathrm{Ag} / \mathrm{AgNO}_{3}(0.1 \mathrm{M}$ in $\mathrm{MeCN}) . E\left(\mathrm{Cp}_{2} \mathrm{Fe}^{+/ 0}\right)$ ranges between 0.05 and $0.10 \mathrm{~V}$.

whereas only upfield shifts were observed for all aliphatic protons upon decreasing the temperature from 80 to $40{ }^{\circ} \mathrm{C}$ (Figure S5 in the Supporting Information), suggesting that hydrophobic-hydrophobic interactions between the long alkyl chains and $\pi-\pi$ interactions between the $\mathrm{C}^{\wedge} \mathrm{N}^{\wedge} \mathrm{C}$ plane of $\mathbf{1 c}$ molecules are involved in the gelation process. ${ }^{4}$

UV-Visible Absorption Spectroscopy. The UV-visible absorption and emission spectral data of all these gold(III) alkyl complexes in $\mathrm{CH}_{2} \mathrm{Cl}_{2}$ solutions at room temperature are given in Table 1. Absorption spectra of selected complexes are shown in Figure 4. Complexes $\mathbf{1 a - c}$ and 2-7 feature strong

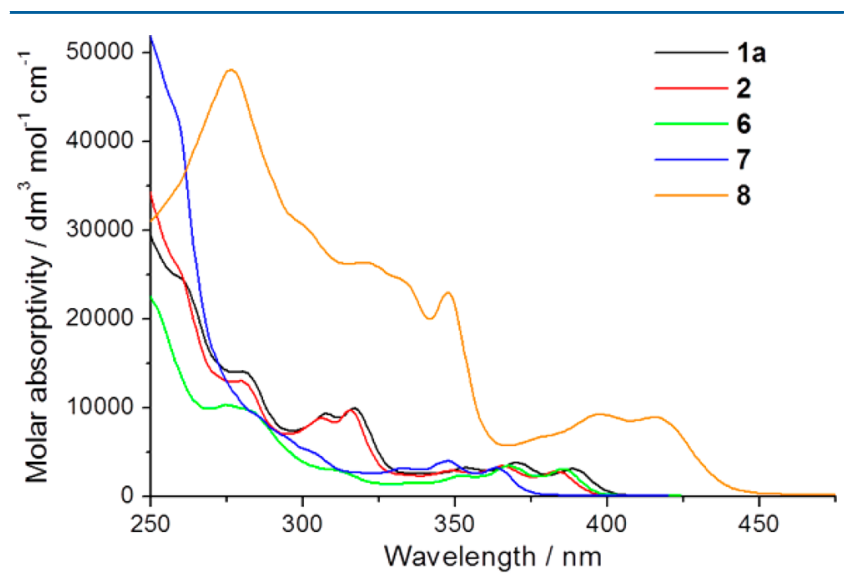

Figure 4. UV-vis absorption spectra of $1 \mathrm{a}, \mathbf{2}$, and 6-8 in $\mathrm{CH}_{2} \mathrm{Cl}_{2}$.

absorption bands $\left(\varepsilon=(1-4) \times 10^{4} \mathrm{dm}^{3} \mathrm{~mol}^{-1} \mathrm{~cm}^{-1}\right)$ at 250-330 nm and moderately intense, vibronic bands $(\varepsilon=(2-$ 4) $\times 10^{3} \mathrm{dm}^{3} \mathrm{~mol}^{-1} \mathrm{~cm}^{-1}$ ) at 350-390 nm. The absorption spectrum of $1 \mathrm{a}$ is insensitive to solvent polarity (maximum shift $4 \mathrm{~nm}$, Figure S3 in the Supporting Information). On the basis of the electrophilic nature of gold(III) and insensitivity of absorption bands to solvent polarity, the absorptions of the gold(III) alkyl complexes are attributable to metal perturbed ${ }^{1} \mathrm{IL}$ transitions localized on the $\left[\mathrm{C}^{\wedge} \mathrm{N}^{\wedge} \mathrm{C}\right]$ ligand. Since the alkyl ligands in the gold(III) complexes do not have a low-lying $\pi$ orbital, the contribution of a LLCT transition which is often proposed in $\left[\mathrm{Au}\left(\mathrm{C}^{\wedge} \mathrm{N}^{\wedge} \mathrm{C}\right) \mathrm{C} \equiv \mathrm{CAr}\right]$ complexes is excluded. ${ }^{2 \mathrm{c}}$ Complex 8, which bears a fluorene unit in the cyclometalating ligand, displays an absorption profile similar to that of its acetylide counterparts, but with a significant blue shift of 14-16 $\mathrm{nm}$ for the absorption peak maxima at $398-416 \mathrm{~nm}(\varepsilon=(8.9-$ 9.3) $\left.\times 10^{3} \mathrm{dm}^{3} \mathrm{~mol}^{-1} \mathrm{~cm}^{-1}\right){ }^{2 \mathrm{j}}$

Luminescence Spectroscopy. With the use of an alkyl ligand as a strong $\sigma$-donor, the as-prepared gold(III) complexes are emissive in solutions at room temperature. As shown in Table 1 and Figures 5 and 6, complexes with substituted 2,6-

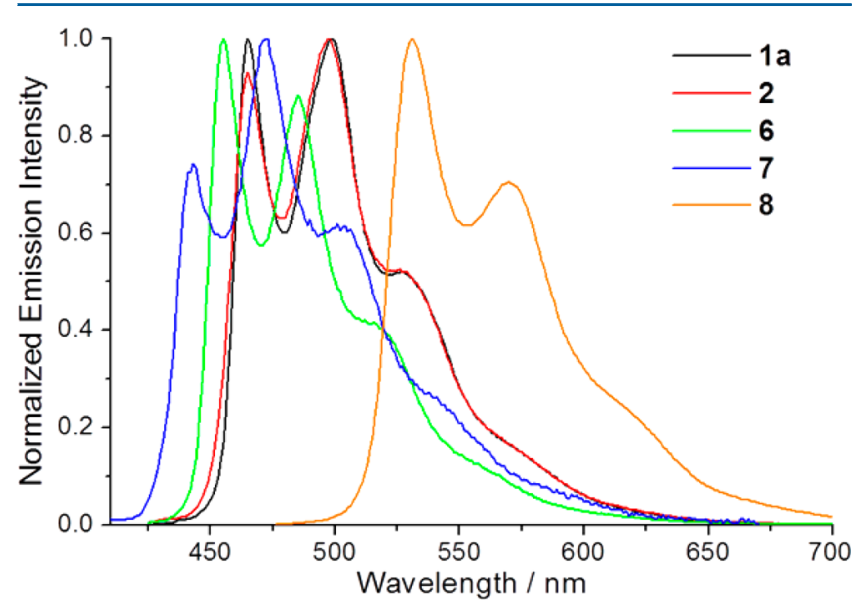

Figure 5. Emission spectra of 1a, 2, and 6-8 in degassed $\mathrm{CH}_{2} \mathrm{Cl}_{2}$.

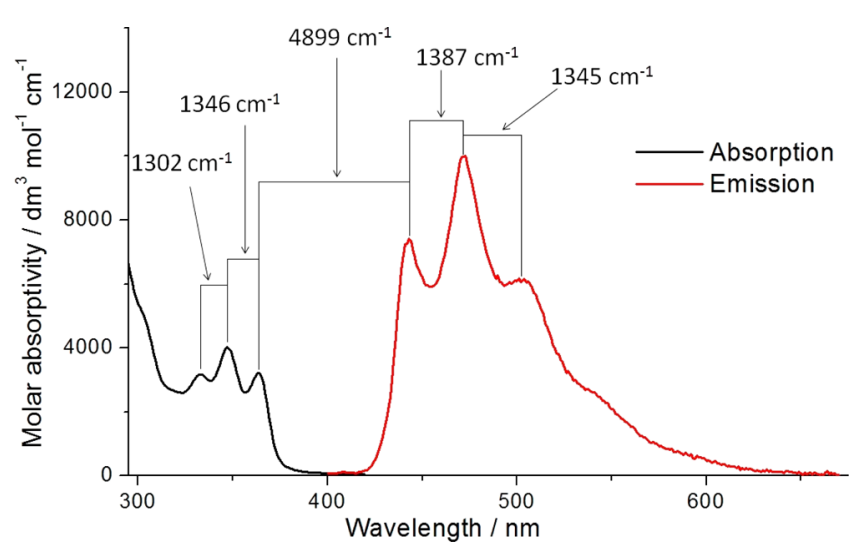

Figure 6. Absorption and emission spectra of 7 in $\mathrm{CH}_{2} \mathrm{Cl}_{2}$, showing the Stokes shift and vibronic spacings. 
diphenylpyridine as the cyclometalating ligand (1a-c, 2-7) display vibronic structured emission with peak maxima at $443-$ 465 and $472-499 \mathrm{~nm}$. The emission color ranges from green $(1 \mathbf{a}-\mathbf{c}, 2-5)$ to blue-green (6) to sky blue (7). Their emission quantum yields and lifetimes in deoxygenated $\mathrm{CH}_{2} \mathrm{Cl}_{2}$ solutions are up to 0.17 and $77 \mu \mathrm{s}$, respectively, both of which are the highest reported values for gold(III) complexes having substituted C-deprotonated 2,6-diphenylpyridine as the cyclometalating ligand. ${ }^{2 c, d, g, o}$ The radiative decay rate constants $\left(k_{\mathrm{r}}\right)$ of these complexes are in the range of $(2.2-2.9) \times 10^{3} \mathrm{~s}^{-1}$, whereas their nonradiative decay rate constants $\left(k_{\mathrm{nr}}\right)$ span from $1.1 \times 10^{4}$ to $2.9 \times 10^{4} \mathrm{~s}^{-1}$, except for 7 , which is an outlier, showing a relatively high $k_{\mathrm{nr}}$ value of $1.4 \times 10^{5} \mathrm{~s}^{-1}$. The excitation spectra monitored at the emission maxima exhibit the same vibronic structure $(300-400 \mathrm{~nm})$ as those observed in the absorption spectra. The emission peak maxima of 1a are insensitive to solvent polarity $(464-466 \mathrm{~nm}$ ) (Figure S3 in the Supporting Information), but the emission quantum yield and lifetime of the complex are significantly affected (toluene, $\Phi=$ 0.09, $\tau=35 \mu \mathrm{s}$; DMF, $\Phi=0.02, \tau=8 \mu \mathrm{s}$; Table S2 in the Supporting Information). The vibronic structured emission, large Stokes shift $\left(4200-5000 \mathrm{~cm}^{-1}\right)$, and small radiative decay rate constant $\left((2-3) \times 10^{3} \mathrm{~s}^{-1}\right)$ all point to an emission origin of a ${ }^{3} \mathrm{IL} \pi-\pi^{*}$ excited state of the $\left[\mathrm{C}^{\wedge} \mathrm{N}^{\wedge} \mathrm{C}\right]$ ligand. The emission self-quenching rate constants of 5,7 , and 8 are $9.4 \times$ $10^{8}, 2.8 \times 10^{8}$, and $1.2 \times 10^{7} \mathrm{dm}^{3} \mathrm{~mol}^{-1} \mathrm{~s}^{-1}$, respectively. Complex 8 displays a yellow emission with a quantum yield and lifetime of 0.40 and $180 \mu \mathrm{s}$ in degassed $\mathrm{CH}_{2} \mathrm{Cl}_{2}$, respectively. The emission of all these complexes in aerated solutions is barely visible to the naked eye.

In glassy solution $(\mathrm{MeOH} / \mathrm{EtOH}, 1 / 4)$ at $77 \mathrm{~K}$, all of these complexes display an intense, vibronic structured emission with energies slightly blue shifted $(2-4 \mathrm{~nm})$ from those recorded in dilute solution at room temperature (Figure 7$)$. The emission lifetimes are greatly lengthened to up to $400 \mu \mathrm{s}$. For example, the emission lifetime of $1 \mathrm{a}$ increases from $43 \mu \mathrm{s}$ at room temperature to $381 \mu \mathrm{s}$ at $77 \mathrm{~K}$.

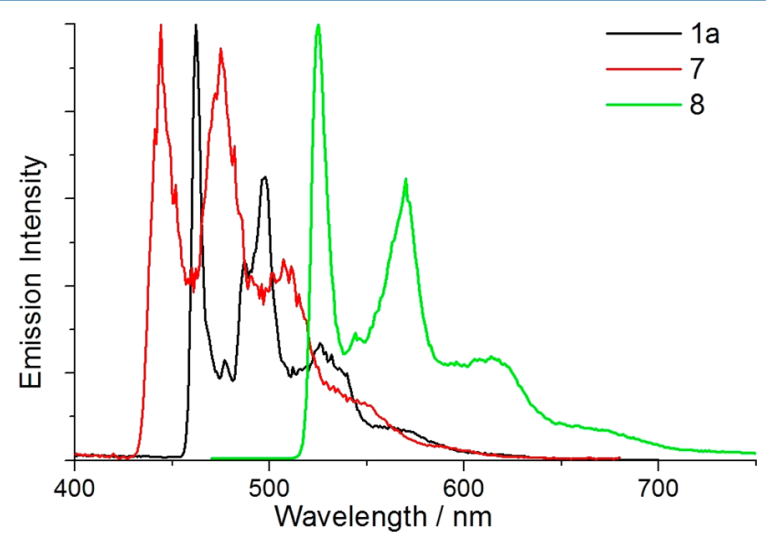

Figure 7. Normalized emission spectra of 1a, 7 , and 8 in glassy solution $(\mathrm{MeOH} / \mathrm{EtOH}, 1 / 4)$ at $77 \mathrm{~K}$.

In the solid state, most of these complexes are weakly emissive at room temperature with emission profiles similar to those in solution but with greatly reduced emission lifetimes $(<1 \mu \mathrm{s})$. Interestingly, complexes 5-7 show a red-shifted emission band in addition to the emission at 430-500 nm. Time-resolved emission measurements conducted on these complexes provide more information on the emission dynamics. As presented in Figure 8, the emissions of $\mathbf{5}$ at $460-550$ and $\sim 650 \mathrm{~nm}$ decay with lifetimes of 0.30 and 0.67
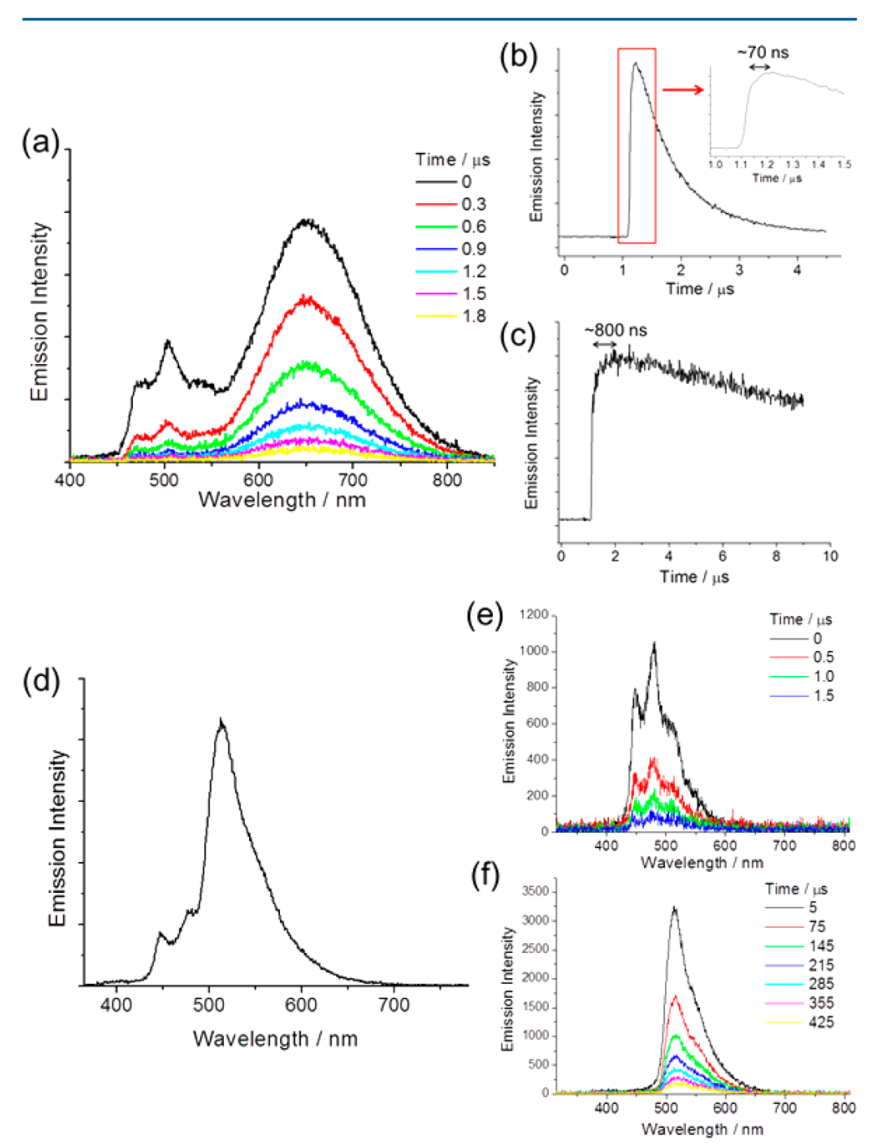

Figure 8. (a) Time-resolved emission spectra of $\mathbf{5}$ in the solid state at room temperature. Emission kinetics of 5 in the solid state at $650 \mathrm{~nm}$ at (b) room temperature and (c) $77 \mathrm{~K}$. (d) Steady-state and (e, f) time-resolved emission spectra of 7 in the solid state at room temperature.

$\mu \mathrm{s}$, respectively, suggesting that the emission comes from different electronic excited states. Emission kinetics recorded for the lower energy emission (Figure $8 \mathrm{~b}$ ) reveal time delays of $\sim 70$ and $\sim 800$ ns to reach the maximum emission intensity after laser pulse excitation $(355 \mathrm{~nm})$ at room temperature and at $77 \mathrm{~K}$, respectively. In PMMA thin film, 5 displays a vibronic structured emission similar to that in solution with a quantum yield of up to 0.13 (Figure S4 in the Supporting Information). However, the low-energy emission at $\sim 650 \mathrm{~nm}$ could not be clearly observed in the film with up to 60 wt \% of 5 in PMMA thin film. For complexes 6 and 7, the emission was found to comprise two components with different lifetimes, which is similar to the case for 5 . Complex 6 displays a short-lived emission $(\tau \approx 60 \mathrm{~ns})$ with $\lambda_{\max }$ at $\sim 435 \mathrm{~nm}$ and a structureless emission with $\lambda_{\max }$ at $555 \mathrm{~nm}$ and a lifetime of $4.1 \mu \mathrm{s}$. For complex 7 , a relatively short lived $(\tau=0.5 \mu \mathrm{s})$ vibronic emission band at $446-515 \mathrm{~nm}$ was observed from 0 to $2 \mu \mathrm{s}$. After this emission faded out, a much longer lived ( $\tau=110 \mu \mathrm{s})$ structureless emission with maximum at $515 \mathrm{~nm}$ was observed.

Concentration-Dependent ${ }^{1} \mathrm{H}$ NMR Spectroscopy. Concentration-dependent ${ }^{1} \mathrm{H}$ NMR spectroscopic measurements were conducted for $\mathbf{1 a}, \mathbf{5}$, and 7 to elucidate the different solid-state emission behaviors. ${ }^{4 \mathrm{e}}$ Figure 9 shows the aromatic region of the ${ }^{1} \mathrm{H}$ NMR spectra of these complexes recorded at 2, 4, and $6 \times 10^{-3} \mathrm{M}$ at $298 \mathrm{~K}$ in $\mathrm{CD}_{2} \mathrm{Cl}_{2}$. The ${ }^{1} \mathrm{H}$ NMR spectra 

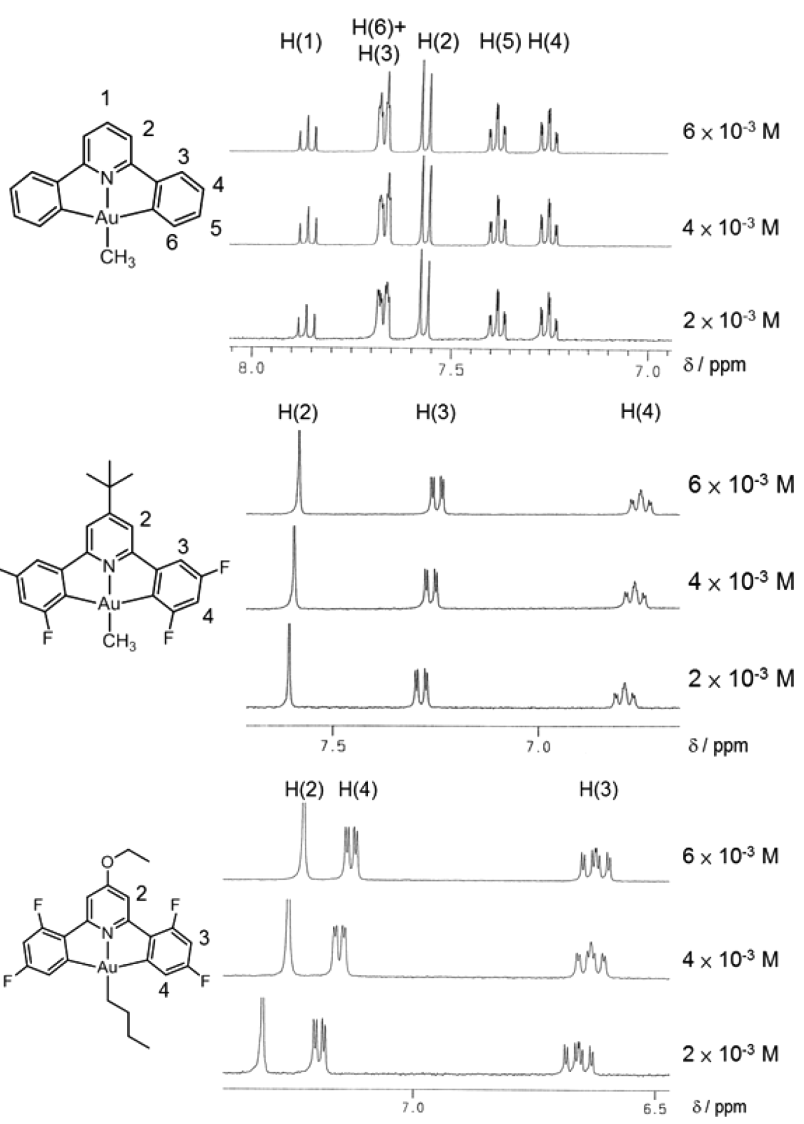

Figure 9. Aromatic region of the ${ }^{1} \mathrm{H}$ NMR spectra of 1a (top), 5 (middle), and 7 (bottom) recorded at 2,4 , and $6 \times 10^{-3} \mathrm{M}$ at $298 \mathrm{~K}$ in $\mathrm{CD}_{2} \mathrm{Cl}_{2}$.

of both 5 and 7 show upfield shifts (up to $0.09 \mathrm{ppm}$ ) for all aromatic proton signals upon increasing concentration. The proton signals of the gold-methyl group of 5 also shifted from 1.89 to $1.82 \mathrm{ppm}$. However, only negligible shifts $(<0.01 \mathrm{ppm})$ were observed for all proton signals of 1a under the same conditions. These data suggest that both 5 and 7 have a stronger proclivity toward aggregation, which may account for why excimeric emissions are observed in the cases of $\mathbf{5}$ and 7 but not 1a.

Electrochemistry. The electrochemical properties of these gold(III) alkyl complexes were investigated by cyclic voltammetry in $\mathrm{CH}_{2} \mathrm{Cl}_{2}$ containing $0.1 \mathrm{M}{ }^{n} \mathrm{Bu}_{4} \mathrm{NPF}_{6}$. The data are summarized in Table 1 , and the cyclic voltammograms of 1a, 7, and 8 are shown in Figure 10. All of the complexes show one irreversible reduction wave with $E_{\mathrm{pc}}$ ranging from -2.04 to $-2.32 \mathrm{~V}$ vs $\mathrm{Ag} / \mathrm{AgNO}_{3}(0.1 \mathrm{M}$ in $\mathrm{MeCN})$. These reduction waves are assigned to reduction at the pyridine moiety. An irreversible oxidation wave is observed for $\mathbf{8}$ with $E_{\mathrm{pa}}$ at $+1.3 \mathrm{~V}$. The potentials of the reduction waves are affected by the substituents on the $\left[\mathrm{C}^{\wedge} \mathrm{N}^{\wedge} \mathrm{C}\right]$ ligand. For example, with the addition of a tert-butyl group at the para position of the pyridine, the $E_{\mathrm{pc}}$ value shows a cathodic shift from $-2.16 \mathrm{~V}$ (1a) to $-2.32 \mathrm{~V}$ (2).

Excited State Properties and Photochemistry. The excited state properties of $\mathbf{1 a}, \mathbf{5}$, and 7 were examined by nanosecond time-resolved absorption difference spectroscopy. Figure 11a shows the excited state absorption difference spectrum of 1a in deoxygenated THF. The spectrum features a broad absorption from 325 to $600 \mathrm{~nm}$ with maxima at 340 and

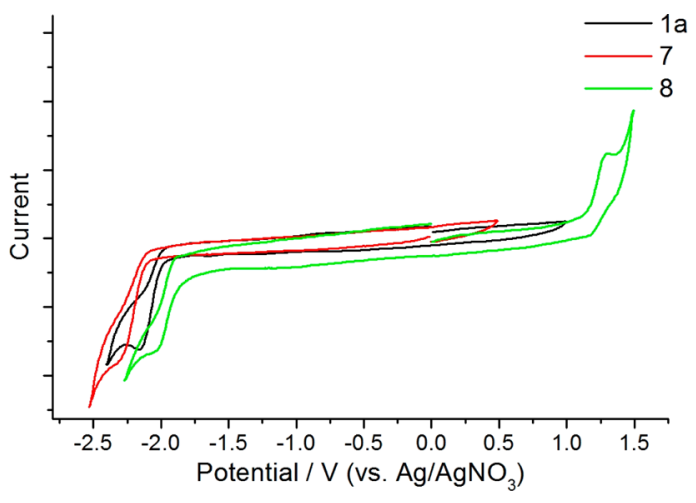

Figure 10. Cyclic voltammograms of $1 \mathrm{a}, 7$, and 8 in $\mathrm{CH}_{2} \mathrm{Cl}_{2}$.

$430 \mathrm{~nm}$. The decay lifetime $(27 \mu \mathrm{s})$ of the absorption at 340 $\mathrm{nm}$ is close to the emission lifetime $(29 \mu \mathrm{s})$ under the same conditions. A similar profile was also observed in deoxygenated toluene. Under oxygen-saturated conditions, a similar absorption profile was observed, but it decayed quickly to the baseline level with a lifetime of $0.13 \mu \mathrm{s}$. In the presence of $0.05 \mathrm{M}$ diisopropylethylamine (DIPEA), a different spectrum with absorption peak maxima at 330, 425, and $600 \mathrm{~nm}$ was observed (Figure 11b). These absorption peaks decayed much more slowly with a time duration of $\sim 400 \mu \mathrm{s}$, which is attributed to the decay of one-electron-reduced la via reductive quenching of triplet excited 1a by DIPEA. The low stability of the as-

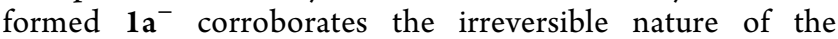
reduction wave of $\mathbf{1 a}$ observed in cyclic voltammetry measurements.

The excited state difference absorption spectrum of $\mathbf{5}$ in $\mathrm{CH}_{2} \mathrm{Cl}_{2}$ at $8 \times 10^{-5} \mathrm{M}$ shares a profile similar to that observed for 1a in THF (Figure 11c). The decay lifetime $(11.9 \mu \mathrm{s})$ of the absorption at $\sim 340 \mathrm{~nm}$ is close to the emission lifetime (11.4 $\mu \mathrm{s})$ under the same conditions. Both lifetimes are much smaller than that observed at $2 \times 10^{-5} \mathrm{M}$ due to emission selfquenching. Complex 7 displayed absorption maxima at $\sim 320$, 430 , and $500 \mathrm{~nm}$ with decay lifetimes of $6.0 \mu \mathrm{s}$ at $1.2 \times 10^{-4} \mathrm{M}$ (Figure 11d). However, it was noted that the absorption profile recorded at $16 \mu$ s showed absorption peaks at $\sim 320$ and 375 $\mathrm{nm}$ which are different from those recorded immediately after the laser excitation, indicating that another species may have been formed from the triplet excited state of 7 . The solution after time-resolved absorption measurement was then subjected to light irradiation at $365 \mathrm{~nm}$ and monitored by UV-vis absorption spectroscopy. Within $30 \mathrm{~min}$, the signal showed a gradual change to another absorption profile with isosbestic points at 332 and $353 \mathrm{~nm}$ (Figure S6 in the Supporting Information). The final species showed similar vibronicstructured absorptions at 340, 359, and $377 \mathrm{~nm}$, which are red-shifted by $8-13 \mathrm{~nm}$ in comparison to $7 .{ }^{1} \mathrm{H}$ NMR spectroscopic analysis revealed that the chloride analogue of 7 was formed in the photolysis reaction.

To shed light on the reason for such reactivity, both $1 \mathrm{a}$ and lb were subjected to photolysis in deoxygenated $\mathrm{CH}_{2} \mathrm{Cl}_{2}$. No significant spectral change was observed in the UV-visible absorption spectrum of 1 a within $10 \mathrm{~min}$, but a gradual red shift was observed in the absorption of $\mathbf{1 b}$. Figure 12 shows the UV-visible absorption spectral change of $\mathbf{1} \mathbf{b}$ upon irradiation. The vibronic structured absorption band of $\mathbf{1 b}$ at $352-387 \mathrm{~nm}$ gradually shifted to $369-406 \mathrm{~nm}$ with isosbestic points at 349 and $376 \mathrm{~nm}$. The absorption spectrum recorded at $90 \mathrm{~min}$ was 

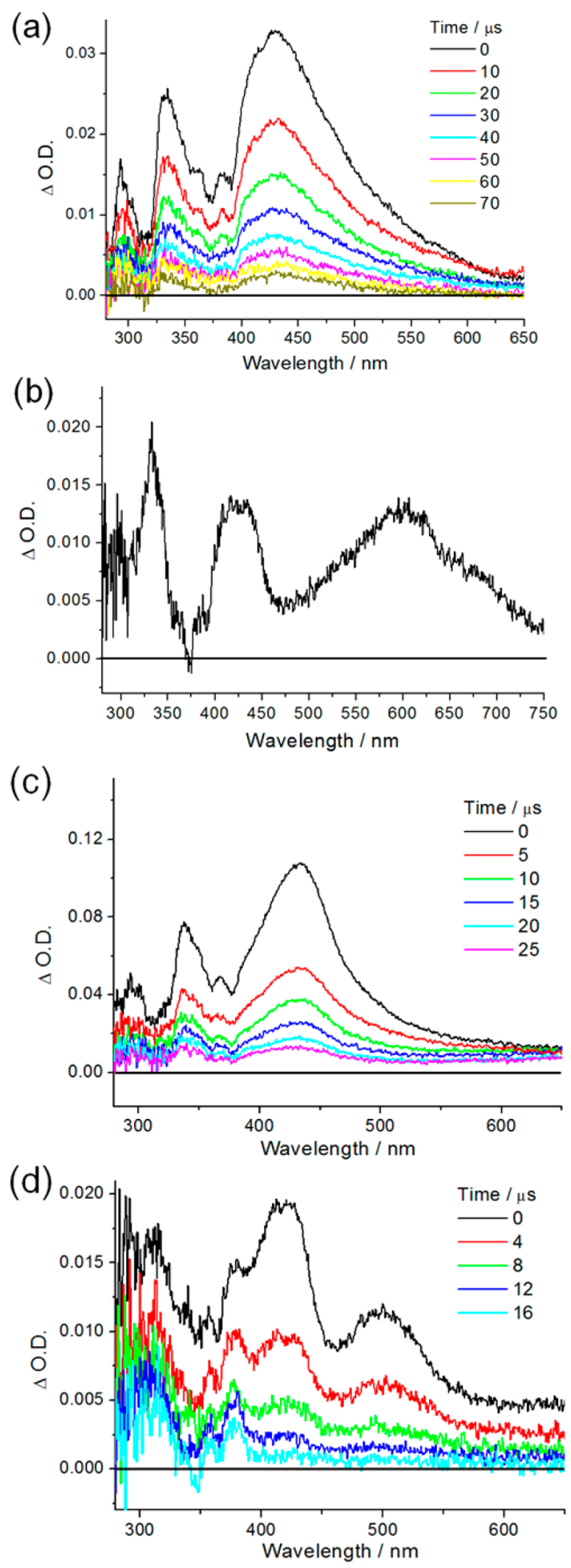

Figure 11. (a) Time-resolved absorption difference spectrum of $\mathbf{1 a}$ in deoxygenated THF and (b) that in the presence of 0.05 M DIPEA. Transient difference absorption spectra of (c) 5 and (d) 7 in deoxygenated $\mathrm{CH}_{2} \mathrm{Cl}_{2}$.

found to be identical with that of $\left[\mathrm{Au}\left(\mathrm{C}^{\wedge} \mathrm{N}^{\wedge} \mathrm{C}\right) \mathrm{Cl}\right]$, which has 2,6-diphenylpyridine as the cyclometalating ligand. The solution also changed from emissive (green) to nonemissive. When the photolysis was conducted in toluene, the absorption spectrum of the solution after $1 \mathrm{~h}$ showed that the absorption of $\mathbf{1 b}$ decreased without formation of a new absorption band

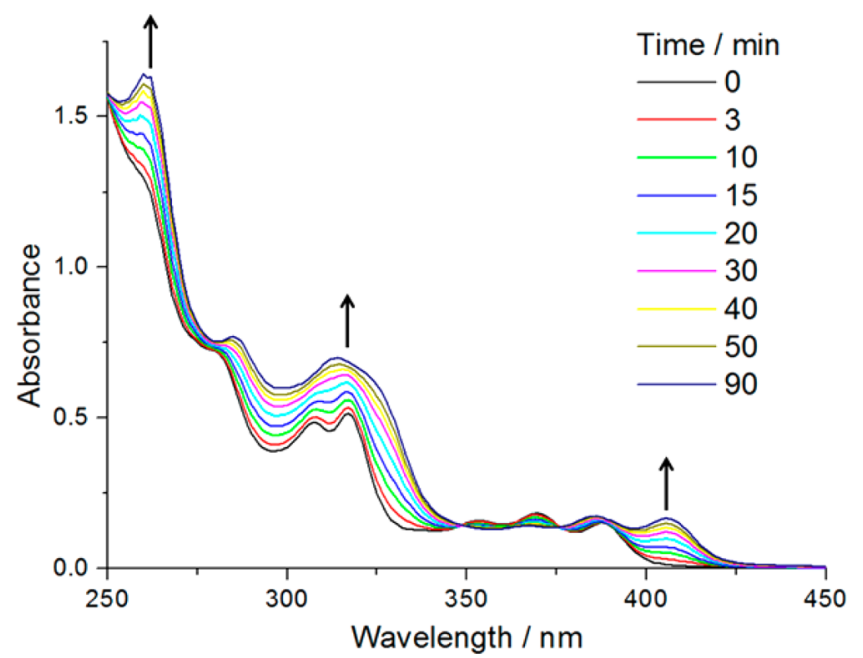

Figure 12. UV-vis absorption spectral change of $\mathbf{1 b}$ recorded at $5 \times$ $10^{-5} \mathrm{M}$ at $298 \mathrm{~K}$ in degassed $\mathrm{CH}_{2} \mathrm{Cl}_{2}$ upon light irradiation at $365 \mathrm{~nm}$. Arrows indicate the change in absorbance upon irradiation.

and the baseline level increased. After irradiation for $12 \mathrm{~h}$, a small amount of dark purple precipitate was observed at the bottom of the cuvette, which suggests the decomposition of $\mathbf{1 b}$ into aggregated gold nanoparticles.

In addition to photoinduced electron transfer, the capacity of 1a to undergo energy transfer was examined with sensitization of triplet-triplet annihilation (TTA) as an example. ${ }^{2 j, 5} 9,10$ Diphenylanthracene (DPA) was chosen as the triplet energy acceptor because the TTA reaction between two ${ }^{3} \mathrm{DPA}^{*}$ molecules produces ${ }^{1} \mathrm{DPA}^{*}$, which decays promptly to give an intense, blue fluorescence. Upon $355 \mathrm{~nm}$ laser pulse excitation, a mixture of $1 \mathrm{a}\left(5 \times 10^{-5} \mathrm{M}\right)$ and DPA $\left(5 \times 10^{-5} \mathrm{M}\right)$ in degassed $\mathrm{CH}_{2} \mathrm{Cl}_{2}$ solution gave a strong delayed fluorescence signal in addition to the vibronic-structured phosphorescence of 1a (Figure 13a). Time-resolved emission measurements
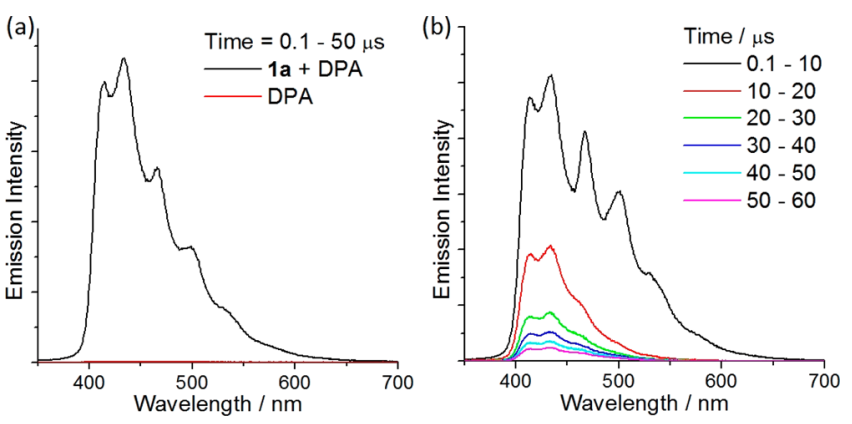

Figure 13. Time-resolved emission spectra ((a) $0.1-50 \mu \mathrm{s}$, (b) $0.1-$ $60 \mu$ s with $10 \mu$ s interval) of a mixture of $1 \mathrm{a}\left(5 \times 10^{-5} \mathrm{M}\right)$ and DPA (5 $\left.\times 10^{-5} \mathrm{M}\right)$ in degassed $\mathrm{CH}_{2} \mathrm{Cl}_{2}$ upon light irradiation at $355 \mathrm{~nm}$.

(Figure 13b) revealed that while both delayed fluorescence of DPA and phosphorescence of 1a were observed in the first 10 $\mu \mathrm{s}$, only a delayed fluorescence of DPA was observed after 10 $\mu \mathrm{s}$. This suggests that the triplet state of 1a was completely quenched by DPA to form ${ }^{3} \mathrm{DPA}^{*}$ within $10 \mu \mathrm{s}$. The as-formed ${ }^{3} \mathrm{DPA}^{*}$ molecule then underwent a TTA reaction with another molecule of ${ }^{3} \mathrm{DPA}^{*}$ to give one molecule of ${ }^{1} \mathrm{DPA}$ in the ground state and one molecule of ${ }^{1} \mathrm{DPA}$ in the excited state, the latter of which rapidly returned to the ground state by radiative decay, resulting in the observed delayed fluorescence of DPA. 
The photochemical reactivity of 1a was also demonstrated by using the oxidative cyanation of a tertiary amine as an example. $^{2 f}$ Initially, when a mixture of $\mathrm{N}$-(4-chlorophenyl)1,2,3,4-tetrahydroisoquinoline (1a; $1 \mathrm{~mol} \%), \mathrm{NaCN}$, and $\mathrm{HOAc}$ in a THF/MeOH mixture (v/v 1/1) was subjected to light irradiation $(\lambda>350 \mathrm{~nm})$ under aerobic conditions, the $\alpha$ cyanated tertiary amine was obtained with $86 \%$ conversion and $87 \%$ yield in $3 \mathrm{~h}$ (Table 2, entry 1 ). When the amount of 1a

Table 2. Conversion and Yield of Oxidative Cyanation of Tertiary Amines by 1a

$\begin{array}{ccccc}\text { amt of } 1 \mathrm{a}(\mathrm{mol} \mathrm{\%}) & \mathrm{R} & \text { conversion (\%) } & \text { yield (\%) } \\ \text { entry }^{a} & 1 & \mathrm{Cl} & 86 & 87 \\ 2 & 1.5 & \mathrm{Cl} & 100 & 86 \\ 3 & 1.5 & \mathrm{Br} & 100 & 80 \\ 4 & 1.5 & \mathrm{H} & 100 & 87 \\ 5 & 1.5 & \mathrm{Me} & 99 & 84 \\ 6 & 1.5 & \mathrm{OMe} & 100 & 80\end{array}$

${ }^{a}$ Conditions: 1a, amine $(0.1 \mathrm{mmol}), \mathrm{NaCN}(0.2 \mathrm{mmol}), \mathrm{HOAc}(0.15$ $\mathrm{mmol})$, THF $(0.8 \mathrm{~mL}), \mathrm{MeOH}(0.8 \mathrm{~mL}), \mathrm{O}_{2}$ bubbling, light $(300 \mathrm{~W}$ xenon lamp, $\lambda>350 \mathrm{~nm}$ ), reaction time $3 \mathrm{~h}$. After the reaction, the solvent was evaporated and the residue was subjected to ${ }^{1} \mathrm{H}$ NMR analysis. Conversions were determined by crude ${ }^{1} \mathrm{H}$ NMR analysis using 5,5'-dimethyl-2,2'-bipyridine as an internal standard, and yields were calculated on the basis of the starting amount of substrate.

was increased to $1.5 \mathrm{~mol} \%$, the desired products could be obtained with excellent conversions (99-100\%) and yields (80-87\%, Table 2, entries 2-6), which are comparable to those obtained by using a cyclometalated iridium(III) complex as the photocatalyst. ${ }^{6}$

Computational Study. All of the complexes investigated in this work have similar radiative and nonradiative decay rate constants $\left(k_{\mathrm{r}} \approx(2.2-2.9) \times 10^{3} \mathrm{~s}^{-1}\right.$ and $k_{\mathrm{nr}} \approx(1.1-2.9) \times 10^{4}$ $\mathrm{s}^{-1}$ ) except for 7 , which has a much higher nonradiative decay rate of $1.40 \times 10^{5} \mathrm{~s}^{-1}$. This higher rate of 7 is contradictory to the energy gap law, which predicts that $k_{\mathrm{nr}}$ should decrease with an increase in the emission energy. DFT/TDDFT calculations have thus been performed on 1a, 6, and 7 to help decipher why the introduction of an alkoxy group at the pyridyl ring of the $\mathrm{C}^{\wedge} \mathrm{N}^{\wedge} \mathrm{C}$ ligand results in an almost 10 -fold increase of the nonradiative decay rate constant.

Table 3 presents the energy gap $\left(\Delta E_{\mathrm{ST}}\right)$ between the lowest singlet excited state $\mathrm{S}_{1}$ and the $n$th triplet excited states $\left(\mathrm{T}_{n} ; n=\right.$ $1,2,3, \ldots)$ and the corresponding spin-orbit coupling matrix elements $\left(H_{\mathrm{SOC}}\right)$. For complexes 1a and 6, there are two triplet excited states below their $S_{1}$ excited state at their respective optimized ground state geometries, of which there is significant SOC between the $S_{1}$ and $T_{1}$ excited states $\left(H_{\text {SOC }}{ }^{2}\right.$ values are on the order of $10^{3} \mathrm{~cm}^{-2}$, comparable to the energy gap between the $S_{1}$ and $T_{1}$ excited states; Table 3). Thus, intersystem crossing (ISC) from the $S_{1}$ to the $T_{1}$ excited state is efficient for both complexes. On the other hand, for 7 , although there are also two triplet excited states below its $S_{1}$ excited state, the SOC between $S_{1}$ and $T_{1}\left(\right.$ or $T_{2}$ ) is more than 1 order of magnitude smaller than the corresponding $S_{1}-T_{1}$ (or $S_{1}-T_{2}$ ) energy gap and, hence, ISC from $S_{1}$ to $T_{1}$ is not a facile path for 7 . Nevertheless, there are two other triplet excited states that have
Table 3. Energy Gap $\left(\Delta E_{\mathrm{ST}} / \mathrm{cm}^{-1}\right)$ and the Associated SpinOrbit Coupling Matrix Element Squared $\left(\mathrm{H}_{\mathrm{SOC}}{ }^{2} / \mathrm{cm}^{-2}\right)$ between the Lowest Singlet Excited State $\left(S_{1}\right)$ and the $n$th Triplet Excited State $\left(T_{n}\right)$ for 1a, 6, and 7 Evaluated at Their Respective Optimized Ground State Geometries

\begin{tabular}{|c|c|c|c|}
\hline complex & $\mathrm{T}_{n}$ & $\Delta E_{\mathrm{ST}}\left(\mathrm{cm}^{-1}\right)^{a}$ & $H_{\mathrm{SOC}}^{2}\left(\mathrm{~cm}^{-2}\right)$ \\
\hline \multirow[t]{2}{*}{ 1a } & $\mathrm{T}_{1}$ & 5895 & $2.91 \times 10^{3}$ \\
\hline & $\mathrm{T}_{2}$ & 5389 & $\sim 0$ \\
\hline \multirow[t]{2}{*}{6} & $\mathrm{~T}_{1}$ & 5333 & $1.66 \times 10^{3}$ \\
\hline & $\mathrm{T}_{2}$ & 5272 & 3.64 \\
\hline \multirow[t]{6}{*}{7} & $\mathrm{~T}_{1}$ & 6449 & $8.38 \times 10^{2}$ \\
\hline & $\mathrm{T}_{2}$ & 5535 & 7.81 \\
\hline & $\mathrm{T}_{3}$ & -602 & $3.28 \times 10^{3}$ \\
\hline & $\mathrm{T}_{4}$ & -1250 & $4.66 \times 10^{2}$ \\
\hline & $\mathrm{T}_{5}$ & -1439 & $7.36 \times 10^{2}$ \\
\hline & $\mathrm{T}_{6}$ & -1712 & $5.24 \times 10^{3}$ \\
\hline
\end{tabular}

large SOC $\left(H_{\mathrm{SOC}^{2}} \approx 10^{3} \mathrm{~cm}^{-2}\right)$ with the $S_{1}$ excited state for 7 : namely, $\mathrm{T}_{3}$ and $\mathrm{T}_{6}$ (Table 3 ). These two triplet excited states are at similar energies at their respective excited state minima and are only $\sim 200 \mathrm{~cm}^{-1}$ above the $S_{1}$ excited state minimum. It is thus expected that $S_{1} \rightarrow T_{3}$ and $S_{1} \rightarrow T_{6}$ (maintaining the state ordering at the FC geometry) are both probable pathways for ISC in 7.

It should be noted that, except in the $\mathrm{T}_{6}$ excited state of 7 , the optimized geometries of the $T_{1}$ excited state for $1 \mathrm{a}$ and 6 and the $T_{3}$ excited state of 7 remain planar (Figure 14). The

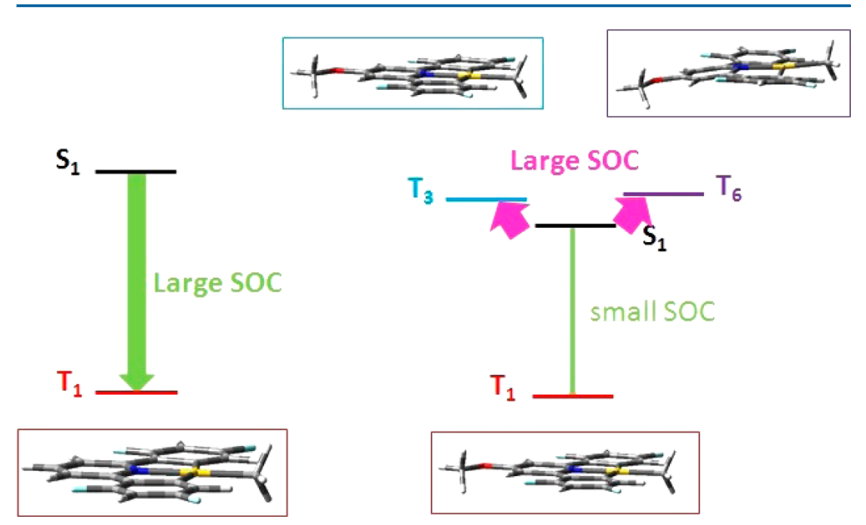

Figure 14. Schematic energy level diagrams of 6 (left) and 7 (right) and the optimized geometries of the relevant triplet excited states. It should be noted that the optimized $\mathrm{T}_{6}$ excited state of 7 exhibits significant deviation from planarity and may contribute to the much higher $k_{\mathrm{nr}}$ value in 7 .

optimized $\mathrm{T}_{6}$ geometry of 7 , on the contrary, deviates from planarity, meaning that ISC from $S_{1}$ to $T_{6}$ will lead to a large structural distortion. As both the optimized $\mathrm{T}_{3}$ and $\mathrm{T}_{6}$ excited states of 7 are of similar energies, ISC from $S_{1}$ may proceed through either the $T_{3}$ or the $T_{6}$ excited state and, if the latter state is populated, the large structural change may contribute to the much higher nonradiative decay rate of 7 .

The difference in SOC between the $S_{1}$ and $T_{1}$ excited states among 1a and 6 (both have large SOC) and 7 (little SOC) is explained as follows. Table 4 gives the contributions of oneelectron excitation configuration state functions (CSFs) to the $\mathrm{T}_{1}$ excited states of $\mathbf{1 a}, \mathbf{6}$, and 7 . The MOs for $\mathbf{1 a}, \mathbf{6}$, and 7 are presented in Figures S24-S26 in the Supporting Information, and selected MOs for 1a and 7 are shown in Figure 15. 
Table 4. Contributions of One-Electron Excitation Configuration State Functions (CSF) to the $T_{1}$ Excited State of 1a, 6, and 7 at Their Respective Optimized $S_{0}$ Geometries $^{a}$

\begin{tabular}{|c|c|c|}
\hline & major & minor \\
\hline \multirow[t]{2}{*}{ 1a } & $\mathrm{H}-3 \rightarrow \mathrm{L}(17)$ & $\begin{array}{l}\mathrm{H}-8 \rightarrow \mathrm{L}+9(2), \mathrm{H}-6 \rightarrow \mathrm{L}(2), \mathrm{H}-4 \rightarrow \mathrm{L}(2), \mathrm{H}-4 \\
\quad \rightarrow \mathrm{L}+2(3)\end{array}$ \\
\hline & $\mathrm{H} \rightarrow \mathrm{L}+1(61)$ & $\mathrm{H}-2 \rightarrow \mathrm{L}+1(6), \mathrm{H}-2 \rightarrow \mathrm{L}+6(2)$ \\
\hline \multirow[t]{2}{*}{6} & $\mathrm{H}-2 \rightarrow \mathrm{L}(15)$ & $\begin{array}{l}\mathrm{H}-7 \rightarrow \mathrm{L}+9(2), \mathrm{H}-6 \rightarrow \mathrm{L}(2), \mathrm{H}-4 \rightarrow \mathrm{L}(4), \mathrm{H}-2 \\
\quad \rightarrow \mathrm{L}+5(2)\end{array}$ \\
\hline & $\mathrm{H} \rightarrow \mathrm{L}+1(61)$ & $\mathrm{H}-1 \rightarrow \mathrm{L}+4(2), \mathrm{H} \rightarrow \mathrm{L}(5)$ \\
\hline \multirow[t]{3}{*}{7} & $\mathrm{H}-2 \rightarrow \mathrm{L}(16)$ & $\mathrm{H}-7 \rightarrow \mathrm{L}+9(2), H-4 \rightarrow L(4), \mathrm{H}-2 \rightarrow \mathrm{L}+2(2)$ \\
\hline & $\mathrm{H} \rightarrow \mathrm{L}(10)$ & $\mathrm{H}-1 \rightarrow \mathrm{L}+4$ (3), $\mathrm{H}-1 \rightarrow \mathrm{L}+4$ (2), $\mathrm{H} \rightarrow \mathrm{L}(5)$ \\
\hline & $\mathrm{H} \rightarrow \mathrm{L}+1(57)$ & \\
\hline
\end{tabular}

${ }^{a_{T}}$ The values in parentheses indicate the percent contribution of each CSF.

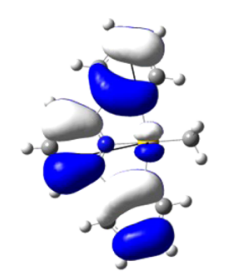

1a $(H)$

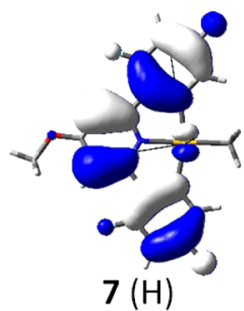

$7(\mathrm{H})$

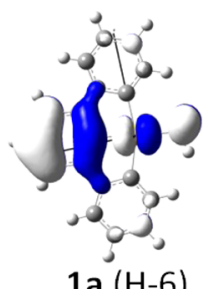

1a $(H-6)$

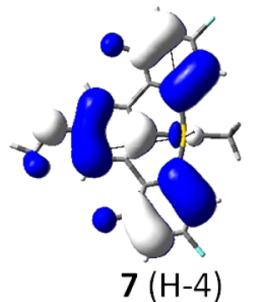

Figure 15. Selected frontier MO surfaces for $1 \mathrm{a}$ and 7 at the optimized $\mathrm{S}_{0}$ geometry.

The $S_{1}$ excited state for all three complexes is dominantly derived from a HOMO $\rightarrow$ LUMO transition with the HOMO being derived mainly from $\pi\left(\mathrm{C}^{\wedge} \mathrm{N}^{\wedge} \mathrm{C}\right)$ with a small \% of $\operatorname{Au}\left(\mathrm{d}_{y z}\right)$ character $(<5 \%)$. For effective SOC with the $S_{1}$ excited state, the coupling triplet excited state should have the occupied MOs derived from $\mathrm{Au}(\mathrm{d}$ orbital) of a different orientation. For both 1a and 6, there is a small contribution (2\%) of the H-6 $\rightarrow$ $\mathrm{L}$ transition to their $\mathrm{T}_{1}$ excited states and $\mathrm{H}-6$ is composed of a $\mathrm{Au}\left(\mathrm{d}_{x z}\right)$ orbital, i.e., a $\mathrm{d}$ orbital with an orientation different from the HOMO $\left(\operatorname{Au}\left(\mathrm{d}_{y z}\right)\right)$. In addition, this H-6 has a considerable amount of $\mathrm{Au}\left(\mathrm{d}_{x z}\right)$ character $\left(\mathrm{Au}\left(\mathrm{d}_{x z}\right): 35 \%\right.$ in 1a and $25 \%$ in 6 ), with the remainder mainly localized on the pyridyl ring (Figures S24 and S25 in the Supporting Information). Thus, though the contribution of this CSF is small, the large percentage of $\mathrm{Au}\left(\mathrm{d}_{x z}\right)$ character in H-6 makes this CSF the dominant contributor to a large SOC (>50\%). On the other hand, for $7, \mathrm{H}-4$ is of $\mathrm{Au}\left(\mathrm{d}_{x z}\right)$ orientation but there is only a small percentage of it in $\mathrm{H}-4(2 \%)$ and so the SOC between $S_{1}$ and $T_{1}$ in 7 is only half that of 6 (Table 3 ). Therefore, the introduction of the electron-donating group at the pyridyl ring of the $\mathrm{C}^{\wedge} \mathrm{N}^{\wedge} \mathrm{C}$ ligand decreases the $\mathrm{Au}\left(\mathrm{d}_{x z}\right)$ character and ISC has to be mediated by higher-lying triplet excited states in 7 , where these triplet excited states are prone to distort.
To examine whether low-lying LMCT or dd excited states contribute to the much higher nonradiative decay rate of 7 , we have also carried out TDDFT optimization of the LMCT/dd excited states. The ${ }^{3} \mathrm{LMCT}$ excited states are calculated to be $1.88,1.77$, and $1.75 \mathrm{eV}$ higher lying than the respective $T_{1}$ excited states of 1a, 6, and 7. Given the similar energy gap between the emitting ${ }^{3} \mathrm{IL}$ and deactivating ${ }^{3} \mathrm{LMCT}$ excited states for $\mathbf{6}$ and 7 , it is envisioned that ${ }^{3} \mathrm{LMCT}$ is not likely to be the deactivating excited state leading to the much higher $k_{\mathrm{nr}}$ observed for 7 .

\section{DISCUSSION}

The development of phosphorescent gold(III) complexes has been gaining momentum in recent years. Much effort has been directed to exploring new ligand systems and applications in OLEDs and photocatalysis. ${ }^{2 f, 7-9}$ As summarized in a review article by Wenger and co-workers, ${ }^{1 \mathrm{~b}}$ luminescent gold(III) complexes are often constructed by the combined use of a cyclometalating bidentate or tridentate ligand and an auxiliary ligand(s) such as arylacetylide. Although arylacetylide was found to provide a strong ligand field and provoke phosphorescence at room temperature, our recent work shows that the high-lying HOMO of arylacetylide may have a detrimental effect on the emissive excited state by providing a nonradiative ${ }^{3} \mathrm{LLCT}$ decay channel $\left({ }^{3}\left[\pi(\mathrm{C} \equiv \mathrm{CAr})-\pi^{*}\right.\right.$ $\left.\left.\left.\left(\mathrm{C}^{\wedge} \mathrm{N}^{\wedge} \mathrm{C}\right)\right]\right)\right)^{2 \mathrm{j}, 3}$ This problem is exacerbated in complexes supported by $\mathrm{C}$-deprotonated 2,6-diphenylpyridine because the HOMO of the ligand is lower lying than that of arylacetylide by $0.64 \mathrm{eV}$. Therefore, we hypothesized that replacing the arylacetylide with a simple alkyl would lead to an increase in both emission quantum yield and lifetime for the complexes supported by the aforementioned cyclometalating ligand.

Cyclometalating $\left[\mathrm{C}^{\wedge} \mathrm{N}^{\wedge} \mathrm{C}\right]$ ligands were obtained by Kröhnke pyridine synthesis or Suzuki coupling, depending on the availability of starting materials. Addition of peripheral substituents (e.g., F, ${ }^{t} \mathrm{Bu}, \mathrm{OEt}$ ) on the ligand is a strategy to tune the triplet emission energy of the complexes. With the exception of the fluorene-containing ligand, all of these ligands formed complexes with mercury(II) and precipitated in ethanol, allowing easy separation from unreacted ligands. The solid obtained by filtration had to be redissolved in $\mathrm{CH}_{2} \mathrm{Cl}_{2}$ and filtered to remove any other salts. The $\left[\mathrm{Au}\left(\mathrm{C}^{\wedge} \mathrm{N}^{\wedge} \mathrm{C}\right) \mathrm{Cl}\right]$ complexes obtained by refluxing the as-formed mercury(II) complexes with $\mathrm{KAuCl}_{4}$ in $\mathrm{MeCN}$ appeared pale yellow or white. The chloride ligand was then substituted by trifluoroacetate because the trifluoroacetate analogue was reported to give the corresponding alkyl complex with a shorter reaction time. ${ }^{2 \mathrm{~h}}$ Insertion of alkyl ligand(s) into cyclometalated gold(III) complexes can be achieved by a transmetalation reaction with tetraalkyltin(IV), ${ }^{10}$ alkyl Grignard reagent, alkyllithium, ${ }^{2 \mathrm{~h}}$ and trialkylaluminum. ${ }^{2 \mathrm{i}}$ Taking both convenience of preparation and safety into consideration, we chose to use the corresponding commercially available alkyllithium reagents for preparing complexes with methyl and butyl groups, whereas an octadecyl Grignard reagent was freshly prepared for the synthesis of $\mathbf{1 c}$. Similar to the report by Tilset, a darkening of the solution arising from formation of metallic gold was observed when the reaction mixture was warmed to room temperature. ${ }^{2 \mathrm{~h}}$ These gold(III) alkyl complexes could be purified by chromatography on $\mathrm{SiO}_{2}$.

In this study, most of the ${ }^{1} \mathrm{H}$ NMR signals of the methyl ligand range from 1.21 to $1.40 \mathrm{ppm}$, which are similar to those found in cyclometalated gold(III) complexes with the methyl 
ligand trans to the pyridine $(1.33-1.62 \mathrm{ppm}) .^{2 \mathrm{~h}, \mathrm{i}}$ The only exception was found in the ${ }^{1} \mathrm{H}$ NMR spectrum of 5 , where the ${ }^{1} \mathrm{H}$ resonance signal of the methyl group appears as a triplet and is rather downfield at $1.86 \mathrm{ppm}$ in comparison to others (1.21$1.40 \mathrm{ppm})$. One possible reason is the existence of an intramolecular $\mathrm{H}-\mathrm{F}$ interaction between the proton of the methyl group and the $\mathrm{F}$ atom on the $\mathrm{C}^{\wedge} \mathrm{N}^{\wedge} \mathrm{C}$ ligand, which withdraws electron density from the proton, leading to a deshielding effect. However, attempts to confirm this by obtaining an X-ray crystal structure of $\mathbf{5}$ were unsuccessful.

Photophysical properties of luminescent gold(III) complexes have been extensively studied in recent years. ${ }^{1}$ It is generally conceived that the HOMO and LUMO of cyclometalated gold(III) complexes mainly localize on phenyl (C) and pyridyl (N) moieties, respectively. As a result, both the absorption and emission energies of a gold(III) complex can be rationally tuned via the utilization of suitable substituents on different parts of the $\mathrm{C}^{\wedge} \mathrm{N}^{\wedge} \mathrm{C}$ ligand. With an eye toward achieving highenergy (e.g., blue) emission, several complexes in this work were prepared with the $\left[\mathrm{C}^{\wedge} \mathrm{N}^{\wedge} \mathrm{C}\right]$ ligands having a tert-butyl or ethoxy group at the para position of the pyridyl ring and fluorine atom(s) at different positions of the phenyl rings. Comparison of the absorption of $\mathbf{1 a}$ with that of $\mathbf{2}$ reveals that the latter shows blue-shifted absorption peaks at higher energies $(5-6 \mathrm{~nm})$, a likely result with the expectation that the LUMO residing on the pyridyl ring would be destabilized by the additional tert-butyl group. In order to lower the energy of the HOMO, fluorine atoms were added to the phenyl rings. For example, substitution with fluorine atoms at the meta positions of phenyl rings proved effective in further blueshifting the absorption of $\mathbf{2}$ at $383 \mathrm{~nm}$ to that of $\mathbf{5}$ at $376 \mathrm{~nm}$. Complex 7, which bears an ethoxy group on pyridine and two fluorine atoms on each phenyl ring, shows the largest blue shift in absorption energy with the last absorption peak at $364 \mathrm{~nm}$. In addition to varying substituents on the cyclometalating ligand, since the pyridyl ring is trans to the auxiliary ligand, auxiliary ligands having varying field strengths are expected to destabilize the LUMO to different extents, thus affecting the energy of the HOMO-LUMO gap. When 1a is compared to the analogue with phenylacetylide (both auxiliary ligands are monoanionic carbon donor ligands), it was found that the vibronic absorption bands at $350-390 \mathrm{~nm}$ of 1a are blueshifted by about $12 \mathrm{~nm}^{2 \mathrm{c}}$ Such a large increase in energy illustrates the much stronger field strength provided by alkyl ligands, in comparison to acetylide, and this underscores the importance of considering the orbital contribution ( $\mathrm{sp}^{3} \mathrm{vs} \mathrm{sp}$ ) of the auxiliary ligand with the same donor atom.

Replacing arylacetylide with alkyl indeed boosted the emission quantum yield and lifetime of these $\left[\mathrm{Au}\left(\mathrm{C}^{\wedge} \mathrm{N}^{\wedge} \mathrm{C}\right)\right]$ complexes. Comparison of $\mathbf{1 a}$ with the phenylacetylide analogue revealed a drastic increase in emission quantum yield and lifetime by more than 100 -fold. ${ }^{2 c}$ There are two possible reasons accounting for this: (i) the alkyl ligand pushes the $\mathrm{d} \sigma^{*}$ orbital of gold(III) to such a high energy that thermal population of electrons from $\pi^{*}$ of the cyclometalating ligand to $\mathrm{d} \sigma^{*}$ of the gold(III), i.e., changing from emissive ${ }^{3} \mathrm{IL}$ to nonemissive ${ }^{3} \mathrm{LMCT}$ excited state, is impossible and (ii) the alkyl ligand does not possess any $\pi$ orbital, thus excluding any possible low-lying ${ }^{3}$ LLCT excited state that may be present in analogous systems with acetylide. When these nonradiative pathways are shut down, the long-lived nature of the ${ }^{3} \mathrm{IL}$ excited state (up to $77 \mu \mathrm{s}$ ) can be measured at room temperature.
The dramatic improvement in luminescence of the ${ }^{3} \mathrm{IL}$ excited state of the cyclometalating ligand upon changing the auxiliary ligand from phenylacetylide to methyl deserves further discussion. It should be stressed that both acetylide and alkyl are strong $\sigma$-carbon donor ligands which effectively enlarge the $\mathrm{d}-\mathrm{d}$ field splitting to such a large extent that nonradiative decay via a low-lying $\mathrm{d}-\mathrm{d}$ excited state is not favorable. The main reason for the low emission quantum yield of acetylide counterparts is due to the presence of a $\pi$ orbital localized on the arylacetylide ligand. This $\pi$ orbital, according to DFT calculations in our previous work, is $0.64 \mathrm{eV}$ higher in energy than the $\pi$-orbital of the $\mathrm{C}^{\wedge} \mathrm{N}^{\wedge} \mathrm{C}$ ligand. ${ }^{2 \mathrm{j}}$ Thus, the charge transfer excited state from the $\pi$-orbital of arylacetylide to the $\pi^{*}$-orbital of the $\mathrm{C}^{\wedge} \mathrm{N}^{\wedge} \mathrm{C}$ ligand (LLCT) plays a significant role during relaxation from the excited state. This facile relaxation pathway involves bond lengthening leading to severe excited state structural distortion and a subsequent dissipation of the emissive ${ }^{3} \mathrm{IL}$ excited state. Rotation of the aryl group of the acetylide ligand along the pyridyl-Au-acetylide axis is not sufficient to cause low luminescence efficiency because gold(III) arylacetylide complexes supported by fluorene functionalized $\mathrm{C}^{\wedge} \mathrm{N}^{\wedge} \mathrm{C}$ ligands also show high emission quantum yields of $0.5-0.6^{2 j, 8 b}$ The success of this class of fluorene-functionalized gold(III) complexes lies in the use of fluorene-based $\mathrm{C}^{\wedge} \mathrm{N}^{\wedge} \mathrm{C}$ ligands so that the increased conjugation at the fluorene destabilizes the HOMO of the cyclometalating ligand and minimizes the energy difference with the $\pi$-orbital of the phenylacetylide. Thus, in addition to looking at the number of strong $\sigma$-donor ligands, the compatibility of these ligands from an orbital-energy point of view, namely the relative order of ligand frontier MOs, must be taken into consideration.

Owing to the strong destabilization of the LUMO offered by the alkyl ligand, the emission of $\mathbf{1 a}$ is at a higher energy (465 $\mathrm{nm})$ than that of the acetylide $(476 \mathrm{~nm})$ and NHC $(479 \mathrm{~nm})$ analogues. ${ }^{2 c, d}$ The emission energy of this class of complex can also be tuned in a way similar to the shifts in absorption energy observed in complexes with different substituents. With the addition of a tert-butyl group and a fluoride at specific positions of the $\mathrm{C}^{\wedge} \mathrm{N}^{\wedge} \mathrm{C}$ ligand, the emission of 4 is blue-shifted by $3 \mathrm{~nm}$ relative to 1a. For 6 and 7, the presence of fluorine atoms at the 2,4-positions of the phenyl ring seems more effective in augmenting the emission energy. With an ethoxy group on pyridine, 7 exhibits the highest energy emission with the first emission peak maximum at $443 \mathrm{~nm}$, whereas 6 has the first maximum at $455 \mathrm{~nm}$. However, the relative intensity of the second emission peak maximum $(472 \mathrm{~nm})$ is about $30 \%$ higher than that of the first $(443 \mathrm{~nm})$ in 7 , suggesting that the structural difference between the excited state and ground state is quite severe; this may account for the low emission quantum yield (0.02) of 7 among this series of complexes. The use of butyl instead of methyl as the auxiliary ligand is not likely to be the reason for the drop in emission quantum yield because the butyl-containing $\mathbf{1 b}$ has an emission quantum yield similar to that of $1 \mathrm{a}(1 \mathrm{a}, 0.11 ; 1 \mathbf{b}, 0.09)$. The relatively high intensity of the second emission maximum of 7 also renders the emission color sky blue $(\mathrm{CIE}$ coordinates $=(0.17,0.24))$ instead of pure blue.

Of particular interest is the observation that both 5 and 7 show an additional low-energy emission band in the solid state. A similar phenomenon has been observed for the [Au$\left.\left(\mathrm{C}^{\wedge} \mathrm{N}^{\wedge} \mathrm{C}\right) \mathrm{C} \equiv \mathrm{CR}\right]$ complexes; the low-energy emission was assigned to dimeric or excimeric emission arising from $\pi \cdots \pi$ 
stacking of the $\left[\mathrm{C}^{\wedge} \mathrm{N}^{\wedge} \mathrm{C}\right]$ ligand. ${ }^{2 \mathrm{c}}$ The emission kinetics of 5 at room temperature revealed a grow-in period of $\sim 70 \mathrm{~ns}$ before reaching the maximum emission intensity after excitation, which corroborates the finding of the kinetics of an excimeric emission of a platinum(II) complex at $700 \mathrm{~nm} .^{11}$ Thus, we assign the high-energy and low-energy emissions of $\mathbf{5}$ as ${ }^{3} \mathrm{IL}$ and excimeric emissions, respectively. At $77 \mathrm{~K}$, the excimeric emission of 5 is red-shifted by $10 \mathrm{~nm}$ and the grow-in time lengthened from $\sim 70$ to $\sim 800 \mathrm{~ns}$, presumably due to a slower excimer formation rate in the low-temperature environment. The upfield shifts observed in the ${ }^{1} \mathrm{H}$ NMR spectra of 5 and 7 upon increasing concentration in $\mathrm{CD}_{2} \mathrm{Cl}_{2}$ at room temperature also suggested their tendency to undergo aggregation.

Electrochemical measurements offered additional insight into how the LUMO energy was affected by the substituents. Addition of an electron-donating group such as tert-butyl at the para position of the pyridine induced a cathodic shift of $0.16 \mathrm{~V}$ (1a vs 2), supporting the assignment that the LUMO is localized in the pyridine moiety. Although the addition of fluorine atoms on the phenyl ring was aimed at lowering the HOMO energy, it was found that substitution with fluorine at the 3- and 5-positions of the phenyl ring induces an anodic shift of the reduction wave from $-2.32 \mathrm{~V}(2)$ to $-2.07 \mathrm{~V}(5)$, presumably because the electron-deficient phenyl rings withdraw electron density from the pyridine by an inductive effect. In contrast, substitution with fluorine at the 2- and 4-positions of the phenyl ring had only a minor effect on the reduction wave $(1,-2.16 \mathrm{~V} ; 6,-2.10 \mathrm{~V})$. Thus, the substitution pattern is also an important consideration when it comes to the tuning of photophysical and electrochemical properties.

The nanosecond time-resolved absorption difference spectrum of 1a shows absorption peak maxima at 340 and $430 \mathrm{~nm}$ which decay with a lifetime $(27 \mu \mathrm{s})$ close to the emission lifetime, suggesting that the absorption originates from the ${ }^{3} \mathrm{IL}$ excited state of 1a. This is also supported by the spectrum's high similarity to the nanosecond time-resolved spectral characteristics of the NHC analogue, ${ }^{7}$ which showed absorption maxima at 340 and $440 \mathrm{~nm}$. When diisopropylethylamine (DIPEA) was present, the absorption profile showed absorptions at 330, 425, and $600 \mathrm{~nm}$, which decayed with a much longer duration of $400 \mu \mathrm{s}$. Since the thermodynamic driving force of the reaction of $* 1$ a with DIPEA is $+0.27 \mathrm{~V}$ $\left(E\left(* 1 \mathbf{a} / 1 \mathbf{a}^{-}\right)=+0.62 \mathrm{~V}, E\left(\mathrm{DIPEA}^{+/ 0}\right)=+0.35 \mathrm{~V}\right.$, vs $\mathrm{Ag} /$ $\mathrm{AgNO}_{3}$ ), the observed long-lived species is assigned as oneelectron-reduced 1a produced via reductive quenching of $* 1$ a by DIPEA (Figure 16). The absorption profile of this long-lived species is also highly similar to that observed for the NHC analogue of 1a with $0.1 \mathrm{M}$ dibenzylamine in degassed DMF,

Reductive quenching:

$$
1 \mathrm{a}^{*}+\text { DIPEA } \longrightarrow 1 \mathrm{a}^{-}+\operatorname{DIPEA}^{\cdot+}
$$

\section{Energy transfer:}

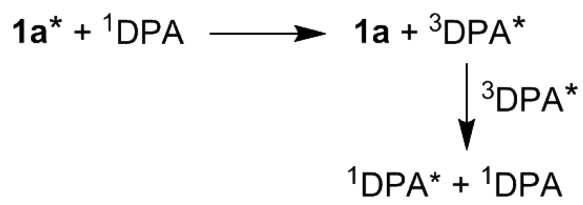

Figure 16. Schematic diagram of the reductive quenching and energy transfer processes of 1a in this study. which showed absorption peak maxima at 330, 440, and 560 nm. ${ }^{7}$

In the literature, examples of energy transfer reactions demonstrated for gold(III) complexes include photoinduced sensitization of singlet oxygen for the oxidation of amines and TTA for energy upconversion. ${ }^{2 f, j}$ In this study, while 1a was found to sensitize the delayed fluorescence of DPA, this process cannot be regarded as energy upconversion because the fluorescence energy of DPA $\left(\lambda_{\max } 410-430 \mathrm{~nm}\right)$ is lower than that of the light photon $(355 \mathrm{~nm})$ required to excite 1 . For gold(III) complexes in general, the lack of absorption of light beyond $450 \mathrm{~nm}$ is in part due to the absence of low-lying ${ }^{1}$ MLCT (metal-to-ligand charge transfer) transitions which are responsible for the absorption in the blue to green spectral region in platinum(II) and iridium(III) complexes. This characteristic arises from the electrophilicity of gold(III), which stabilizes the occupied $5 \mathrm{~d} \pi$ orbital to such an extent that the latter is lower lying than the highest occupied $\mathrm{d} \pi$ orbital of the cyclometalating ligand, rendering the ${ }^{1} \mathrm{IL}$ transition the lowest lying absorption transition in most cases. Attempts to narrow the ${ }^{1} \mathrm{IL}$ transition by increasing the conjugation of the cyclometalating ligand with the use of two fluorene moieties have been made, but the absorption of the resultant complex only shows vibronic structured absorption peak maxima at 423 and $446 \mathrm{~nm}$ with a weak absorption tail ending at $470-480 \mathrm{~nm} .{ }^{8 \mathrm{~b}}$ Thus, the development of nonporphyrin-type phosphorescent gold(III) complexes showing strong absorption beyond $450 \mathrm{~nm}$ remains a challenge.

Studies on the application of gold(III) complexes in lightinduced reactions are relatively rare in comparison to those of iridium(III), ruthenium(II), and platinum(II) complexes, ${ }^{12}$ presumably due to the limited number of gold(III) complexes displaying decent emission quantum yields at room temperature. As the photochemical reactivities of gold(III) complexes with $\mathrm{NHC}$, acetylide, or chloride as auxiliary ligands have been explored by us and other groups, ${ }^{2 a, f, 7,9}$ we are interested in whether these gold(III) alkyl complexes possess similar properties. In this study, photoinduced oxidative cyanation of tertiary amines was used as an example to illustrate the photochemical reactivity of gold(III) alkyl complexes with $\mathbf{1 a}$ as a representative. It was found that 1a was capable of catalyzing the formation of $\alpha$-cyanated tertiary amines under light irradiation with excellent conversions and yields at $1.5 \mathrm{~mol} \%$ loading. Although the amount of catalyst required is more than that needed in our previous study with $\left[\mathrm{Au}\left(\mathrm{C}^{\wedge} \mathrm{N}^{\wedge} \mathrm{C}\right) \mathrm{NHC}\right]^{+}$as catalyst, ${ }^{2 \mathrm{f}}$ this finding reveals that gold(III) alkyl complexes could have sufficient stability to act as catalysts for light-induced reactions, and this also suggests that other metal alkyl complexes may possess rich photochemical properties which are not yet discovered because of a general expectation of their poor stability.

\section{CONCLUSION}

In summary, this study demonstrates the use of the alkyl ligand as an excellent alternative to acetylide, NHC, and aryl ligands in pincer-type gold(III) complexes. With the advantages of absence of a low-lying $\pi$-orbital in the alkyl ligands and their strong $\sigma$-donating ability, population of both the LLCT and the highly structurally distorted, deactivating LMCT excited state can be prevented. When these nonemissive decay pathways are kept at bay, these complexes display emissive and long-lived ${ }^{3} \mathrm{IL}$ excited states with emission quantum yields and lifetimes of up to 0.40 and $180 \mu \mathrm{s}$, respectively, in solution at room 
temperature. This work highlights that, in addition to considering the donor strength of the auxiliary ligand, the nature of its contributing frontier molecular orbitals is an important yet largely overlooked factor that may have a decisive influence on the luminescent properties.

\section{EXPERIMENTAL SECTION}

Materials and Reagents. All chemicals, unless otherwise noted, were purchased from commercial sources. All solvents for reaction and photophysical studies were of HPLC grade. The ligands (except 2,6diphenylpyridine) were prepared by methods developed by Kröhnke from the respective acetophenones and benzaldehydes or by Suzuki coupling, and the gold(III) complexes were synthesized according to literature methods. ${ }^{2 \mathrm{~b}, 13,14}$ 4-Ethoxy-2,6-dibromopyridine (starting material for ligand of 7) was synthesized according to a reported procedure. ${ }^{15}$

Physical Measurements and Instrumentation. Nuclear magnetic resonance spectra were recorded on DPX-300, -400 , and -600 Bruker FT-NMR spectrometer with chemical shifts (in ppm) relative to tetramethylsilane (for $\mathrm{CDCl}_{3}$ ) or nondeuterated solvent residual signal. Unless otherwise stated, all NMR spectra were recorded at room temperature. Mass spectra (FAB and $\mathrm{EI}$ ) were recorded on a Finnigan MAT 95 mass spectrometer. Elemental analyses were performed at the Institute of Chemistry of the Chinese Academy of Sciences, Beijing, People's Republic of China. All absorption spectra were recorded on a Hewlett-Packard 8453 diode array spectrophotometer. Steady-state emission spectra were recorded on a SPEX Fluorolog-3 spectrophotometer. Solutions for photophysical studies were degassed by using a high-vacuum line in a two-compartment cell with five freeze-pump-thaw cycles. Low-temperature $(77 \mathrm{~K})$ emission spectra for glassy-state and solid-state samples were recorded in quartz tubes ( $4 \mathrm{~mm}$ internal diameter) placed in a liquid nitrogen Dewar flask with quartz windows. The emission quantum yield was measured with 9,10-bis(phenylethynyl)anthracene $(\Phi=0.85)$ in benzene as reference and calculated by $\Phi_{\mathrm{s}}=\Phi_{\mathrm{r}}\left(B_{\mathrm{r}} / B_{\mathrm{s}}\right)\left(n_{\mathrm{s}} / n_{\mathrm{r}}\right)^{2}\left(D_{\mathrm{s}} / D_{\mathrm{r}}\right)$, in which the subscripts $s$ and $r$ refer to sample and reference standard solutions, respectively, $n$ is the refractive index of the solvents, $D$ is the integrated emission intensity, and $\Phi$ is the luminescence quantum yield. The excitation intensity $B$ is calculated by $B=1-10^{-A L}$, where $A$ is the absorbance at the excitation wavelength and $L$ is the optical path length $(\lambda=1 \mathrm{~cm}$ in all cases). The refractive indices of the solvents at room temperature were taken from standard sources. Emission quantum yields of thin film samples were measured with a Hamamatsu C11347 Quantaurus-QY Absolute PL quantum yield measurement system. The thin films were prepared by drop-casting from a chlorobenzene solution containing the gold(III) complex with PMMA. The solvent was evaporated at $60^{\circ} \mathrm{C}$, and translucent films were obtained. The emission lifetime measurements were performed on a Quanta Ray GCR 150-10 pulsed Nd:YAG laser system. Errors for $\lambda$ values $( \pm 1 \mathrm{~nm}), \tau( \pm 10 \%)$, and $\Phi( \pm 10 \%)$ are estimated. Nanosecond time-resolved emission measurements were performed on a LP920-KS Laser Flash Photolysis Spectrometer (Edinburgh Instruments Ltd., Livingston, U.K.). The excitation source was the 355 $\mathrm{nm}$ output (third harmonic) of a Nd:YAG laser (Spectra-Physics Quanta-Ray Lab-130 Pulsed Nd:YAG laser). The signals were processed by a PC plug-in controller with L900 software. The preparation of samples for the measurements was the same as that for steady-state emission measurements. Cyclic voltammetric measurements were performed on a Princeton Applied Research electrochemical analyzer (Model 273 A Potentiostat/Galvanostat) with a conventional three-compartment cell. A solution of $0.1 \mathrm{M}^{n} \mathrm{Bu}_{4} \mathrm{NPF}_{6}$ in $\mathrm{CH}_{2} \mathrm{Cl}_{2}$ was used as a supporting electrolyte for the electrochemical measurements. All solutions used in electrochemical measurements were deaerated by bubbling with argon, and the measurements were done at room temperature. $\mathrm{Ag} / \mathrm{AgNO}_{3}(0.1 \mathrm{M}$ in $\mathrm{MeCN})$, a glassycarbon electrode, and a platinum wire were used as reference electrode, working electrode, and counter electrode, respectively; ferrocene was used as an internal reference. SEM images were taken on a Hitachi S-4800 field emission scanning electron microscope operating at $3.0 \mathrm{kV}$. SEM samples were prepared by drop-casting suspensions onto silicon wafers and air-dried. TEM and SAED were performed on a Philips Tecnai G2 20 S-TWIN transmission electron microscope with an accelerating voltage of $200 \mathrm{kV}$. The TEM images and SAED patterns were taken by a Gatan Model 794 MultiScan Camera. TEM samples were prepared by depositing a few drops of suspensions on the Formvar-coated copper grids, and the excess solvent was removed by a piece of filter paper.

Crystal Structure Determination. X-ray diffraction data were collected on a Bruker X8 Proteum diffractometer. The diffraction images were interpreted and the diffraction intensities were integrated by using the program SAINT. The crystal structure was solved by direct methods employing the SHELXS-97 program and refined by full-matrix least squares using the program SHELXL-97. ${ }^{16}$

Computational Methods. In this work, the hybrid density functional $\mathrm{PBE}^{17}$ was employed for all calculations using the program package G09. ${ }^{18}$ The $6-31 G^{*}$ basis set ${ }^{19}$ was used for all atoms except $\mathrm{Au}$, which was described by the Stuttgart relativistic pseudopotential and its accompanying basis set (ECP60MWB) ${ }^{20}$ Solvent effects were also included by means of the polarizable continuum model (PCM), ${ }^{21}$ and default parameters were used for the solvent, dichloromethane. No symmetry constraints were applied in geometry optimizations. For the singlet ground state $\left(S_{0}\right)$, the restricted density functional theory (RDFT) formalism was employed while the triplet excited states $\left(T_{1}\right.$ and $\left.{ }^{3} \mathrm{LMCT} /{ }^{3} \mathrm{dd}\right)$ were optimized using time-dependent density functional theory (TDDFT) ${ }^{22}$ Frequency calculations were performed on the optimized structures to ensure that they are minimum energy structures by the absence of imaginary frequency (i.e., NImag $=0$ ). Stability calculations were also performed for all the optimized structures to ensure that all the wave functions obtained were stable. Vertical excitation energies of the singlet and triplet excited states were calculated at the optimized ground state geometries on the basis of TDDFT using the linear response approximation (LR-PCM). Direct spin-orbit coupling matrix elements $\left(H_{\mathrm{SOC}}\right)$ between the singlet and triplet excited states were evaluated at the optimized ground state geometries, and the detailed procedures were reported in our previous work. 3,23

General Procedure for the Synthesis of Gold(III) Alkyl Complexes. For all complexes except 1c, an alkyllithium solution (1.5 equiv) was added dropwise to an anhydrous THF solution/ suspension of the corresponding $\left[\mathrm{Au}\left(\mathrm{C}^{\wedge} \mathrm{N}^{\wedge} \mathrm{C}\right)\left(\mathrm{OCOCF}_{3}\right)\right](\sim 100$ $\mathrm{mg})$ at $-78{ }^{\circ} \mathrm{C}$ and stirred for $1 \mathrm{~h}$. The reaction mixture was warmed to room temperature and stirred for another $1 \mathrm{~h}$. After removal of solvent in vacuo, the product was purified by column chromatography on $\mathrm{SiO}_{2}$ using $\mathrm{CH}_{2} \mathrm{Cl}_{2}$ as eluent.

1a: yield $58 \mathrm{mg}(71 \%)$. MS (+FAB) $m / z: 441.9\left[\mathrm{M}^{+}\right] .{ }^{1} \mathrm{H}$ NMR $\left(400 \mathrm{MHz}, \mathrm{CD}_{2} \mathrm{Cl}_{2}\right): \delta 7.82(\mathrm{t}, 1 \mathrm{H}, J=7.7 \mathrm{~Hz}), 7.64(\mathrm{~d}, 4 \mathrm{H}, J=8.0$ $\mathrm{Hz}), 7.52(\mathrm{~d}, 2 \mathrm{H}, J=8.0 \mathrm{~Hz}), 7.36(\mathrm{t}, 2 \mathrm{H}, J=6.5 \mathrm{~Hz}), 7.23(\mathrm{t}, 2 \mathrm{H}, J=$ $8.1 \mathrm{~Hz}), 1.27(\mathrm{~s}, 3 \mathrm{H}) .{ }^{13} \mathrm{C}$ NMR $\left(100.6 \mathrm{MHz}, \mathrm{CD}_{2} \mathrm{Cl}_{2}\right): \delta 166.8$, $162.4,151.3,141.3,133.1,130.6,126.1,125.3,116.6,1.8$. Anal. Calcd for $\mathrm{C}_{18} \mathrm{H}_{14} \mathrm{AuN}$ : C, 48.99; H, 3.20; N, 3.17. Found: C, 49.22; H, 3.19; $\mathrm{N}, 3.12$.

1b: yield $48 \mathrm{mg}(54 \%)$. MS (+FAB) $m / z: 484.0\left[\mathrm{M}^{+}\right] .{ }^{1} \mathrm{H}$ NMR (300 MHz, $\mathrm{D}_{6}$-DMSO): $\delta 8.08(\mathrm{t}, 1 \mathrm{H}, J=7.9 \mathrm{~Hz}), 7.92(\mathrm{~m}, 4 \mathrm{H}), 7.61$ $(\mathrm{d}, 2 \mathrm{H}, J=7.2 \mathrm{~Hz}), 7.41(\mathrm{t}, 2 \mathrm{H}, J=7.3 \mathrm{~Hz}), 7.27(\mathrm{t}, 2 \mathrm{H}, J=7.5 \mathrm{~Hz})$, $1.90(\mathrm{t}, 2 \mathrm{H}, J=6.7 \mathrm{~Hz}$ ), 1.80 (quint, $2 \mathrm{H}, J=7.3 \mathrm{~Hz}$ ), 1.53 (sextet, $2 \mathrm{H}$, $J=7.3 \mathrm{~Hz}), 0.92(\mathrm{t}, 3 \mathrm{H}, J=7.3 \mathrm{~Hz}) .{ }^{13} \mathrm{C} \operatorname{NMR}\left(151 \mathrm{MHz}, \mathrm{CD}_{2} \mathrm{Cl}_{2}\right): \delta$ $168.2,162.7,151.3,141.8,133.9,131.2,126.7,125.8,117.1,33.9,27.7$, 26.7, 14.6. Anal. Calcd for $\mathrm{C}_{21} \mathrm{H}_{20} \mathrm{AuN}$ : C, 52.18; H, 4.17; N, 2.90 . Found: C, 51.89; H, 4.10; N, 2.88.

1c: a freshly prepared octadecyl Grignard reagent was used instead of alkyllithium solution; yield $95 \mathrm{mg}(75 \%)$. MS (+FAB) $\mathrm{m} / \mathrm{z}: 680.1$ $\left[\mathrm{M}^{+}\right] .{ }^{1} \mathrm{H}$ NMR $\left(400 \mathrm{MHz}, \mathrm{D}_{6}\right.$-DMSO, $\left.50{ }^{\circ} \mathrm{C}\right): \delta 8.06(\mathrm{t}, 1 \mathrm{H}, J=8.4$ $\mathrm{Hz}), 7.89(\mathrm{~m}, 4 \mathrm{H}), 7.63(\mathrm{~d}, 2 \mathrm{H}, J=7.2 \mathrm{~Hz}), 7.40(\mathrm{t}, 2 \mathrm{H}, J=7.3 \mathrm{~Hz})$ $7.27(\mathrm{t}, 2 \mathrm{H}, J=7.6 \mathrm{~Hz}), 1.94(\mathrm{t}, 2 \mathrm{H}, J=6.8 \mathrm{~Hz}), 1.84$ (quint, $2 \mathrm{H}, J=$ $7.1 \mathrm{~Hz}$ ), 1.48 (quint, $2 \mathrm{H}, J=6.8 \mathrm{~Hz}), 1.35(\mathrm{~m}, 2 \mathrm{H}), 1.23(\mathrm{~m}, 26 \mathrm{H})$ $0.85(\mathrm{t}, 3 \mathrm{H}, J=7.0 \mathrm{~Hz}) .{ }^{13} \mathrm{C} \mathrm{NMR}\left(151 \mathrm{MHz}, \mathrm{CD}_{2} \mathrm{Cl}_{2}\right): 168.2,162.8$, $151.3,141.8,133.9,131.2,126.7,125.8,117.1,34.7,32.5,31.5,30.4$ 30.3, 30.2, 29.9, 23.3. Anal. Calcd for $\mathrm{C}_{35} \mathrm{H}_{48} \mathrm{AuN}$ : C, 61.84; H, 7.12; $\mathrm{N}, 2.06$. Found: C, 62.10; H, 7.22; N, 1.95 . 
2: yield $72 \mathrm{mg}(57 \%)$. MS (+FAB) $m / z: 497.9\left[\mathrm{M}^{+}\right] .{ }^{1} \mathrm{H}$ NMR (400 $\left.\mathrm{MHz}, \mathrm{CD}_{2} \mathrm{Cl}_{2}\right): \delta 7.71(\mathrm{~d}, 2 \mathrm{H}, J=7.6 \mathrm{~Hz}), 7.66(\mathrm{~d}, 2 \mathrm{H}, J=7.2 \mathrm{~Hz})$, $7.57(\mathrm{~s}, 2 \mathrm{H}), 7.36(\mathrm{t}, 2 \mathrm{H}, J=7.3 \mathrm{~Hz}), 7.25(\mathrm{t}, 2 \mathrm{H}, J=7.6 \mathrm{~Hz}), 1.43(\mathrm{~s}$, $9 \mathrm{H}), 1.26(\mathrm{~s}, 3 \mathrm{H}) .{ }^{13} \mathrm{C}$ NMR $\left(151 \mathrm{MHz}, \mathrm{CD}_{2} \mathrm{Cl}_{2}\right): \delta 167.4,167.0$, 162.5, 151.6, 133.7, 131.0, 126.6, 125.6, 114.5, 36.5, 30.8, 2.0. Anal. Calcd for $\mathrm{C}_{22} \mathrm{H}_{22} \mathrm{AuN}$ : C, 53.13; H, 4.46; N, 2.82. Found: C, 53.44; $\mathrm{H}$, $4.61 ; \mathrm{N}, 2.80$.

3: yield $43 \mathrm{mg}(52 \%)$. MS (+FAB) $m / z: 478.0\left[\mathrm{M}^{+}\right] .{ }^{1} \mathrm{H}$ NMR (400 $\left.\mathrm{MHz}, \mathrm{CD}_{2} \mathrm{Cl}_{2}\right): \delta 7.82(\mathrm{t}, 1 \mathrm{H}, J=8.0 \mathrm{~Hz}), 7.65(\mathrm{~m}, 2 \mathrm{H}), 7.43(\mathrm{~d}, 2 \mathrm{H}, J$ $=8.0 \mathrm{~Hz}), 7.32(\mathrm{~d}, 2 \mathrm{H}, J=8.0 \mathrm{~Hz}), 6.89(\mathrm{t}, 2 \mathrm{H}, J=8.6 \mathrm{~Hz}), 1.21(\mathrm{~s}$, $3 \mathrm{H}) ;{ }^{19} \mathrm{~F}$ NMR $\left(376 \mathrm{MHz}, \mathrm{CD}_{2} \mathrm{Cl}_{2}\right): \delta=-109.4 .{ }^{13} \mathrm{C}$ NMR (151 $\left.\mathrm{MHz}, \mathrm{CD}_{2} \mathrm{Cl}_{2}\right): \delta 169.8(\mathrm{~d}, J=3.4 \mathrm{~Hz}), 165.6,163.9,161.7,146.9$ (d, $J$ $=1.8 \mathrm{~Hz}), 127.8(\mathrm{~d}, J=8.1 \mathrm{~Hz}), 120.2(\mathrm{~d}, J=18.1 \mathrm{~Hz}), 116.9,113.4$ $(\mathrm{d}, J=23.0 \mathrm{~Hz}), 2.8$. Anal. Calcd for $\mathrm{C}_{18} \mathrm{H}_{12} \mathrm{AuF}_{2} \mathrm{~N}$ : C, 45.30; H, 2.53; $\mathrm{N}, 2.93$. Found: C, 45.20; $\mathrm{H}, 2.77 ; \mathrm{N}, 3.05$.

4: yield $38 \mathrm{mg}(45 \%)$. MS (+FAB) $m / z: 533.9\left[\mathrm{M}^{+}\right] .{ }^{1} \mathrm{H}$ NMR (400 $\left.\mathrm{MHz}, \mathrm{CD}_{2} \mathrm{Cl}_{2}\right): \delta 7.73(\mathrm{~d}, 2 \mathrm{H}, J=8.5 \mathrm{~Hz}), 7.49(\mathrm{~s}, 2 \mathrm{H}), 7.36(\mathrm{~d}, 2 \mathrm{H}, J$ $=8.0 \mathrm{~Hz}), 6.91(\mathrm{t}, 2 \mathrm{H}, J=8.6 \mathrm{~Hz}), 1.42(\mathrm{~s}, 9 \mathrm{H}), 1.26(\mathrm{~s}, 3 \mathrm{H}) .{ }^{19} \mathrm{~F}$ NMR $\left(376 \mathrm{MHz}, \mathrm{CD}_{2} \mathrm{Cl}_{2}\right): \delta-109.8 .{ }^{13} \mathrm{C} \mathrm{NMR}\left(151 \mathrm{MHz}, \mathrm{CD}_{2} \mathrm{Cl}_{2}\right)$ : $\delta 169.7,165.5,163.8,161.2,147.2(\mathrm{~d}, J=2.6 \mathrm{~Hz}), 127.5(\mathrm{~d}, J=7.9$ $\mathrm{Hz}), 120.2(J=18.0 \mathrm{~Hz}), 114.3,113.3(\mathrm{~d}, J=23.0 \mathrm{~Hz}), 36.5,30.8,2.3$. Anal. Calcd for $\mathrm{C}_{22} \mathrm{H}_{20} \mathrm{AuF}_{2} \mathrm{~N}$ : C, 49.54; H, 3.78; N, 2.63. Found: C, 49.76; H, 4.01; N, 2.36.

5: yield $46 \mathrm{mg}(54 \%)$. MS (+FAB) $m / z: 569.9\left[\mathrm{M}^{+}\right] .{ }^{1} \mathrm{H}$ NMR (400 $\left.\mathrm{MHz}, \mathrm{CDCl}_{3}\right): \delta 7.72(\mathrm{~s}, 2 \mathrm{H}), 7.17(\mathrm{~d}, 2 \mathrm{H}, J=8.9 \mathrm{~Hz}), 6.73(\mathrm{t}, 2 \mathrm{H}, J$ $=8.7 \mathrm{~Hz}), 1.86(\mathrm{~s}, 3 \mathrm{H}), 1.44(\mathrm{~s}, 9 \mathrm{H}) .{ }^{19} \mathrm{~F}$ NMR $\left(376 \mathrm{MHz}, \mathrm{CDCl}_{3}\right): \delta$ -93.4, -113.4. ${ }^{13} \mathrm{C}$ NMR not recorded due to low solubility. Anal. Calcd for $\mathrm{C}_{22} \mathrm{H}_{18} \mathrm{AuF}_{4} \mathrm{~N}$ : C, 46.41; H, 3.19; N, 2.46. Found: C, 46.09; $\mathrm{H}, 3.20$; N, 2.41 .

6: yield $34 \mathrm{mg}(35 \%)$. MS (+FAB) $m / z: 513.2\left[\mathrm{M}^{+}\right] .{ }^{1} \mathrm{H}$ NMR (400 $\mathrm{MHz}, \mathrm{D}_{6}$-DMSO, $\left.60{ }^{\circ} \mathrm{C}\right): \delta 8.17(\mathrm{t}, 1 \mathrm{H}, J=6.5 \mathrm{~Hz}), 7.95(\mathrm{~d}, 2 \mathrm{H}, J=$ $6.1 \mathrm{~Hz}), 7.21(\mathrm{~d}, 2 \mathrm{H}, J=5.3 \mathrm{~Hz}), 7.07(\mathrm{t}, 2 \mathrm{H}, J=8.5 \mathrm{~Hz}), 1.24(\mathrm{~s}$, $3 \mathrm{H}) .{ }^{19} \mathrm{~F}$ NMR $\left(376 \mathrm{MHz}, \mathrm{CD}_{2} \mathrm{Cl}_{2}\right): \delta-105.4,-107.5 .{ }^{13} \mathrm{C}$ NMR not recorded due to low solubility. Anal. Calcd for $\mathrm{C}_{18} \mathrm{H}_{10} \mathrm{AuF}_{4} \mathrm{~N}$ : C, 42.12; H, 1.96; N, 2.73. Found: C, 42.00; H, 2.01; N, 2.76.

7: yield $38 \mathrm{mg}(37 \%)$. MS (+FAB) $\mathrm{m} / z: 599.9\left[\mathrm{M}^{+}\right] .{ }^{1} \mathrm{H}$ NMR (300 $\left.\mathrm{MHz}, \mathrm{CD}_{2} \mathrm{Cl}_{2}\right): \delta 7.20(\mathrm{~s}, 2 \mathrm{H}), 7.11(\mathrm{~d}, 2 \mathrm{H}, J=7.1 \mathrm{~Hz}), 6.61(\mathrm{td}, 2 \mathrm{H}$, $J=10.6,2.4 \mathrm{~Hz}), 4.13(\mathrm{q}, 2 \mathrm{H}, J=7.0 \mathrm{~Hz}), 1.72(\mathrm{~m}, 4 \mathrm{H}), 1.47(\mathrm{~m}$, $5 \mathrm{H}), 0.94(\mathrm{t}, 3 \mathrm{H}, J=7.3 \mathrm{~Hz}) .{ }^{19} \mathrm{~F}$ NMR $\left(376 \mathrm{MHz}, \mathrm{CD}_{2} \mathrm{Cl}_{2}\right): \delta$ $-107.0,-109.0 .{ }^{13} \mathrm{C}$ NMR $\left(151 \mathrm{MHz}, \mathrm{CD}_{2} \mathrm{Cl}_{2}\right): \delta 170.4(\mathrm{~d}, J=73.0$ $\mathrm{Hz}), 165.5(\mathrm{~d}, J=10.3 \mathrm{~Hz}), 163.5(\mathrm{dd}, J=69.8,10.3 \mathrm{~Hz}), 161.6(\mathrm{~d}, J=$ $10.8 \mathrm{~Hz}), 160.1(\mathrm{~d}, J=5.8 \mathrm{~Hz}), 133.8,115.8(\mathrm{~d}, J=17.8 \mathrm{~Hz}), 107.5(\mathrm{~d}$, $J=19.0 \mathrm{~Hz}), 102.6(\mathrm{t}, J=26.6 \mathrm{~Hz}), 63.4,30.2,28.5,27.4,14.7,14.5$. Anal. Calcd for $\mathrm{C}_{23} \mathrm{H}_{20} \mathrm{AuF}_{4} \mathrm{NO}$ : C, 46.09; H, 3.36; N, 2.34. Found: C, 46.40; H, 3.44; N, 2.30.

8: yield $60 \mathrm{mg}(57 \%)$. MS $(+\mathrm{FAB}) \mathrm{m} / z: 718.0\left[\mathrm{M}^{+}\right] .{ }^{1} \mathrm{H}$ NMR $(400$ $\left.\mathrm{MHz}, \mathrm{CD}_{2} \mathrm{Cl}_{2}\right): \delta 8.06(\mathrm{~s}, 1 \mathrm{H}), 7.83(\mathrm{~m}, 4 \mathrm{H}), 7.72(\mathrm{~m}, 4 \mathrm{H}), 7.56-$ $7.63(\mathrm{~m}, 3 \mathrm{H}), 7.34-7.42(\mathrm{~m}, 4 \mathrm{H}), 7.26(\mathrm{t}, 1 \mathrm{H}, J=7.34 \mathrm{~Hz}), 2.04(\mathrm{t}$, $4 \mathrm{H}, J=8.3 \mathrm{~Hz}), 1.40(\mathrm{~s}, 3 \mathrm{H}), 1.08(\mathrm{~m}, 4 \mathrm{H}), 0.56-0.68(\mathrm{~m}, 10 \mathrm{H}) .{ }^{13} \mathrm{C}$ NMR (151 MHz, $\left.\mathrm{CD}_{2} \mathrm{Cl}_{2}\right): \delta 167.6,166.3,163.3,163.2,154.7,152.0$, $151.3,150.0,149.3,144.2,141.8,138.9,133.8,131.2,130.5,129.8$, $128.0,127.9,127.4,126.7,125.8,124.8,123.4,120.7,120.5,115.6$, 115.1, 55.5, 40.9, 26.6, 23.7, 14.2, 2.5. Anal. Calcd for $\mathrm{C}_{39} \mathrm{H}_{38} \mathrm{AuN}$ : C, 65.27; H, 5.34; N, 1.95. Found: C, 65.33; H, 5.53; N, 2.15.

\section{ASSOCIATED CONTENT}

\section{S Supporting Information}

The Supporting Information is available free of charge on the ACS Publications website at DOI: 10.1021/acs.inorgchem.7b00180.

Synthesis details, characterization data, photophysical properties, and computational details (PDF)

Crystallographic data (CIF)

Crystallographic data (CIF)

\section{AUTHOR INFORMATION}

\section{Corresponding Author}

*E-mail for C.-M.C.: cmche@hku.hk.

ORCID $\odot$

Wai-Pong To: 0000-0002-6820-243X

Notes

The authors declare no competing financial interest.

\section{ACKNOWLEDGMENTS}

This work was funded by the National Key Basic Research Program of China (No. 2013CB834802), the Hong Kong Research Grants Council (HKU 17330416), the University Grants Committee Areas of Excellence Scheme (AoE/P-03/ 08), and Guangdong Special Project of the Introduction of Innovative R\&D Teams and GuangDong Aglaia Optoelectronic Materials Co., Ltd. We thank Dr. X. Chang for solving the Xray crystal structure of 4 .

\section{REFERENCES}

(1) (a) Yam, V. W.-W.; Cheng, E. C.-C. Highlights on the recent advances in gold chemistry-a photophysical perspective. Chem. Soc. Rev. 2008, 37, 1806-1813. (b) Bronner, C.; Wenger, O. S. Luminescent cyclometalated gold(III) complexes. Dalton Trans. 2011, 40, 12409-12420. (c) Nevado, C.; Kumar, R. Cyclometalated $\mathrm{Au}(\mathrm{III})$ complexes: synthesis, reactivity and physicochemical properties. Angew. Chem., Int. Ed. 2017, 56, 1994-2015.

(2) (a) Chan, C.-W.; Wong, W.-T.; Che, C.-M. Gold(III) photooxidants, Photophysical, photochemical properties, and crystal structure of a luminescent cyclometalated gold(III) complexes of 2,9diphenyl-1,10-phenanthroline. Inorg. Chem. 1994, 33, 1266-1272. (b) Wong, K.-H.; Cheung, K.-K.; Chan, M. C.-W.; Che, C.-M. Application of 2,6-diphenylpyridine as a tridentate $\left[\mathrm{C}^{\wedge} \mathrm{N}^{\wedge} \mathrm{C}\right]$ dianionic ligand in organogold(III) chemistry. Structural and spectroscopic properties of mono- and binuclear transmetalated gold(III) complexes. Organometallics 1998, 17, 3505-3511. (c) Wong, K. M.-C.; Hung, L.L.; Lam, W. H.; Zhu, N.; Yam, V. W.-W. A class of luminescent cyclometalated alkynylgold(III) complexes: synthesis, characterization, and electrochemical, photophysical, and computational studies of $\left[\mathrm{Au}\left(\mathrm{C}^{\wedge} \mathrm{N}^{\wedge} \mathrm{C}\right)(\mathrm{C} \equiv \mathrm{C}-\mathrm{R})\right]\left(\mathrm{C}^{\wedge} \mathrm{N}^{\wedge} \mathrm{C}=\kappa^{3} \mathrm{C}, \mathrm{N}, \mathrm{C}\right.$ bis-cyclometalated 2,6diphenylpyridyl). J. Am. Chem. Soc. 2007, 129, 4350-4365. (d) Au, V. K.-M.; Wong, K. M.-C.; Zhu, N.; Yam, V. W.-W. Luminescent cyclometalated $\mathrm{N}$-heterocyclic carbene-containing organogold(III) complexes: synthesis, characterization, electrochemistry, and photophysical studies. J. Am. Chem. Soc. 2009, 131, 9076-9085. (e) Garg, J. A.; Blacque, O.; Fox, T.; Venkatesan, K. Stable and tunable phosphorescent neutral cyclometalated $\mathrm{Au}(\mathrm{III})$ diaryl complexes. Inorg. Chem. 2010, 49, 11463-11472. (f) To, W.-P.; Tong, G. S.M.; Lu, W.; Ma, C.; Liu, J.; Chow, A. L.-F.; Che, C.-M. Luminescent organogold(III) complexes with long-lived triplet excited states for light-induced oxidative $\mathrm{C}-\mathrm{H}$ bond functionalization and hydrogen production. Angew. Chem., Int. Ed. 2012, 51, 2654-2657. (g) Roşca, D.-A.; Smith, D. A.; Bochmann, M. Cyclometalated gold(III) hydroxides as versatile synthons for $\mathrm{Au}-\mathrm{N}, \mathrm{Au}-\mathrm{C}$ complexes and luminescent compounds. Chem. Commun. 2012, 48, 7247-7249. (h) Langseth, E.; Görbitz, C. H.; Heyn, R. H.; Tilset, M. Versatile methods for preparation of new cyclometalated gold(III) complexes. Organometallics 2012, 31, 6567-6571. (i) Smith, D. A.; Roşca, D.-A.; Bochmann, M. Selective $\mathrm{Au}-\mathrm{C}$ cleavage in $\left(\mathrm{C}^{\wedge} \mathrm{N}^{\wedge} \mathrm{C}\right) \mathrm{Au}(\mathrm{III})$ aryl and alkyl pincer complexes. Organometallics 2012, 31, 5998-6000. (j) To, W.-P.; Chan, K. T.; Tong, G. S.-M.; Ma, C.; Kwok, W.-M.; Guan, X.; Low, K.-H.; Che, C.-M. Strongly luminescent gold(III) complexes with long-lived excited states: high emission quantum yields, energy up-conversion, and nonlinear optical properties. Angew. Chem., Int. Ed. 2013, 52, 6648-6652. (k) Herbst, A.; Bronner, C.; Dechambenoit, P.; Wenger, O. S. Gold complexes with tridentate cyclometalating and NHC ligands: a search for new photoluminescent gold(III) 
compounds. Organometallics 2013, 32, 1807-1814. (1) Hung, F.-F.; To, W.-P.; Zhang, J.-J.; Ma, C.; Wong, W.-Y.; Che, C.-M. Watersoluble luminescent cyclometalated gold(III) complexes with cischelating bis( $N$-heterocyclic carbene) ligands: synthesis and photophysical properties. Chem. - Eur. J. 2014, 20, 8604-8614. (m) Szentkuti, A.; Bachmann, M.; Garg, J. A.; Blacque, O.; Venkatesan, K. Monocyclometalated gold(III) monoaryl complexes - a new class of triplet phosphors with highly tunable and efficient emission properties. Chem. - Eur. J. 2014, 20, 2585-2596. (n) David, B.; Monkowius, U.; Rust, J.; Lehmann, C. W.; Hyzak, L.; Mohr, F. Gold(III) compounds containing a chelating, dicarbanionic ligand derived from 4,4'-di-tert-butylbiphenyl. Dalton Trans. 2014, 43, 11059-11066. (o) Roşca, D.-A.; Fernandez-Cestau, J.; Romanov, A. S.; Bochmann, M. Synthesis, C-N cleavage and photoluminescence of gold(III) isocyanide complexes. J. Organomet. Chem. 2015, 792, 117122. (p) Browne, A. R.; Deligonul, N.; Anderson, B. L.; Zeller, M.; Hunter, A. D.; Gray, T. G. Cyclometalated (boroxinato)gold(III) complexes from arrested transmetalation. Chem. Commun. 2015, 51, 15800-15803. (q) Fernández-Moreira, V.; Cámara, J.; Smirnova, E. S.; Koshevoy, I. O.; Laguna, A.; Tunik, S. P.; Blanco, M. C.; Gimeno, M. $\mathrm{C}$. Tuning the energy emission from violet to yellow with bidentate phosphine gold(III) complexes. Organometallics 2016, 35, 1141-1150. (r) Nilakantan, L.; McMillin, D. R.; Sharp, P. R. Emissive biphenyl cyclometalated gold(III) diethyl dithiocarbamate complexes. Organometallics 2016, 35, 2339-2347. (s) Currie, L.; Fernandez-Cestau, J.; Rocchigiani, L.; Bertrand, B.; Lancaster, S. J.; Hughes, D. L.; Duckworth, H.; Jones, S. T. E.; Credgington, D.; Penford, T. J.; Bochmann, M. Luminescent gold(III) thiolates: supramolecular interactions trigger and control switchable photoemissions from bimolecular excited states. Chem. - Eur. J. 2017, 23, 105-113.

(3) Tong, G. S. M.; Chan, K. T.; Chang, X.; Che, C.-M. Theoretical studies on the photophysical properties of luminescent pincer gold(III) arylacetylide complexes: the role of $\pi$-conjugation at the C-deprotonated $\left[\mathrm{C}^{\wedge} \mathrm{N}^{\wedge} \mathrm{C}\right]$ ligand. Chem. Sci. 2015, 6, 3026-3037.

(4) (a) Lu, W.; Chan, K. T.; Wu, S.-X.; Chen, Y.; Che, C.-M. Quest for an intermolecular $\mathrm{Au}(\mathrm{III}) \bullet \bullet \bullet \mathrm{Au}(\mathrm{III})$ interaction between cyclometalated gold(III) cations. Chem. Sci. 2012, 3, 752-755. (b) Zhang, J.-J.; Lu, W.; Sun, R. W.-Y.; Che, C.-M. Organogold(III) supramolecular polymers for anticancer treatment. Angew. Chem., Int. Ed. 2012, 51, 4882-4886. (c) Au, V. K.-M.; Zhu, N.; Yam, V. W.-W. Luminescent metallogels of bis-cyclometalated alkynylgold(III) complexes. Inorg. Chem. 2013, 52, 558-567. (d) Xiao, X.-S.; Kwong, W.-L.; Guan, X.; Yang, C.; Lu, W.; Che, C.-M. Platinum(II) and gold(III) allenylidene complexes: phosphorescence, self-assembled nanostructures and cytotoxicity. Chem. - Eur. J. 2013, 19, 9457-9462. (e) Yim, K.-C.; Lam, E. S.-H.; Wong, K. M.-C.; Au, V. K.-M.; Ko, C.C.; Lam, W. H.; Yam, V. W.-W. Synthesis, characterization, selfassembly, gelation, morphology and computational studies of alkynylgold(III) complexes of 2,6-bis(benzimidazol-2'-yl)pyridine derivatives. Chem. - Eur. J. 2014, 20, 9930-9939.

(5) Cui, X.; Zhao, J.; Mohmood, Z.; Zhang, C. Accessing the longlived triplet excited states in transition-metal complexes: molecular design rationales and applications. Chem. Rec. 2016, 16, 173-188.

(6) Rueping, M.; Zhu, S.; Koenigs, R. M. Visible-light photoredox catalyzed oxidative Strecker reaction. Chem. Commun. 2011, 47, 12709-12711.

(7) Sun, C.-Y.; To, W.-P.; Wang, X.-L.; Chan, K.-T.; Su, Z.-M.; Che, C.-M. Metal-organic framework composites with luminescent gold(III) complexes. Strongly emissive and long-lived excited states in open air and photo-catalysis. Chem. Sci. 2015, 6, 7105-7111.

(8) (a) Au, V. K.-M.; Wong, K. M.-C.; Tsang, D. P.-K.; Chan, M.-Y.; Zhu, N.; Yam, V W.-W. High-efficiency green organic light-emitting devices utilizing phosphorescent bis-cyclometalated alkynylgold(III) complexes. J. Am. Chem. Soc. 2010, 132, 14273-14278. (b) Cheng, G.; Chan, K. T.; To, W.-P.; Che, C.-M. Color tunable organic lightemitting devices with external quantum efficiency over $20 \%$ based on strongly luminescent gold(III) complexes having long-lived emissive excited states. Adv. Mater. 2014, 26, 2540-2546. (c) Tang, M.-C.; Tsang, D. P.-K.; Wong, Y.-C.; Chan, M.-Y.; Wong, K. M.-C.; Yam, V.
W.-W. Bipolar gold(III) complexes for solution-processable organic light-emitting devices with a small efficiency roll-off. J. Am. Chem. Soc. 2014, 136, 17861-17868.

(9) (a) Zehnder, T. N.; Blacque, O.; Venkatesan, K. Luminescent monocyclometalated cationic gold(III) complexes: synthesis, photophysical characterization and catalytic investigations. Dalton Trans. 2014, 43, 11959-11972. (b) Xue, Q.; Xie, J.; Jin, H.; Cheng, Y.; Zhu, $\mathrm{C}$. Highly efficient visible-light-induced aerobic oxidative $\mathrm{C}-\mathrm{C}, \mathrm{C}-\mathrm{P}$ coupling from $\mathrm{C}-\mathrm{H}$ bonds catalyzed by a gold(III)-complex. Org. Biomol. Chem. 2013, 11, 1606-1609. (c) Yu, Z.-T.; Liu, X.-L.; Yuan, Y.-J.; Li, Y.-H.; Chen, G.-H.; Zou, Z.-G. Evaluation of bis-cyclometalated alkynylgold(III) sensitizers for water photoreduction to hydrogen. Dalton Trans. 2016, 45, 17223-17232.

(10) Venugopal, A.; Shaw, A. P.; Törnroos, K. W.; Heyn, R. H.; Tilset, M. Synthesis of a coordinately labile gold(III) methyl complex. Organometallics 2011, 30, 3250-3253.

(11) Williams, J. A. G.; Beeby, A.; Davies, E. S.; Weinstein, J. A.; Wilson, C. An alternative route to highly luminescent platinum(II) complexes: cyclometalation with $\hat{\mathrm{N}} \hat{\mathrm{C}} \mathrm{N}$-coordinating dipyridylbenzene ligands. Inorg. Chem. 2003, 42, 8609-8611.

(12) Prier, C. K.; Rankic, D. A.; MacMillan, D. W. C. Visible light photoredox catalysis with transition metal complexes: applications in organic synthesis. Chem. Rev. 2013, 113, 5322-5363.

(13) Kröhnke, F. The specific synthesis of pyridines and oligopyridines. Synthesis 1976, 1976, 1-24.

(14) Wilkinson, A. J.; Puschmann, H.; Howard, J. A. K.; Foster, C. E.; Williams, J. A. G. Luminescent complexes of iridium(III) containing $\hat{\mathrm{N}} \hat{\mathrm{C} N}$-coordinating terdentate ligands. Inorg. Chem. 2006, 45, 86858699.

(15) Liu, Z.; Yao, Y.; Kogiso, M.; Zheng, B.; Deng, L.; Qiu, J. J.; Dong, S.; Lv, H.; Gallo, J. M.; Li, X.-N.; Song, Y. Inhibition of cancerassociated mutant isocitrate dehydrogenases: synthesis, structureactivity relationship, and selective antitumor activity. J. Med. Chem. 2014, 57, 8307-8318.

(16) Sheldrick, G. M. A short history of SHELX. Acta Crystallogr., Sect. A: Found. Crystallogr. 2008, 64, 112-122.

(17) Adamo, C.; Barone, V. Toward reliable density functional methods without adjustable parameters: the PBE0 model. J. Chem. Phys. 1999, 110, 6158-6169.

(18) Frisch, M. J.; Trucks, G. W.; Schlegel, H. B.; Scuseria, G. E.; Robb, M. A.; Cheeseman, J. R.; Scalmani, G.; Barone, V.; Mennucci, B.; Petersson, G. A.; Nakatsuji, H.; Caricato, M.; Li, X.; Hratchian, H. P.; Izmaylov, A. F.; Bloino, J.; Zheng, G.; Sonnenberg, J. L.; Hada, M.; Ehara, M.; Toyota, K.; Fukuda, R.; Hasegawa, J.; Ishida, M.; Nakajima, T.; Honda, Y.; Kitao, O.; Nakai, H.; Vreven, T.; Montgomery, J. A., Jr.; Peralta, J. E.; Ogliaro, F.; Bearpark, M.; Heyd, J. J.; Brothers, E.; Kudin, K. N.; Staroverov, V. N.; Kobayashi, R.; Normand, J.; Raghavachari, K.; Rendell, A.; Burant, J. C.; Iyengar, S. S.; Tomasi, J.; Cossi, M.; Rega, N.; Millam, J. M.; Klene, M.; Knox, J. E.; Cross, J. B.; Bakken, V.; Adamo, C.; Jaramillo, J.; Gomperts, R.; Stratmann, R. E.; Yazyev, O.; Austin, A. J.; Cammi, R.; Pomelli, C.; Ochterski, J. W.; Martin, R. L.; Morokuma, K.; Zakrzewski, V. G.; Voth, G. A.; Salvador, P.; Dannenberg, J. J.; Dapprich, S.; Daniels, A. D.; Farkas, Ö.; Foresman, J. B.; Ortiz, J. V.; Cioslowski, J.; Fox, D. J. Gaussian 09, Revision D.01; Gaussian, Inc., Wallingford, CT, 2009.

(19) (a) Francl, M. M.; Petro, W. J.; Hehre, W. J.; Binkley, J. S.; Gordon, M. S.; DeFree, D. J.; Pople, J. A. Self-consistent molecular orbital methods. XXIII. A polarization-type basis set for second-row elements. J. Chem. Phys. 1982, 77, 3654-3665. (b) Hariharan, P. C.; Pople, J. A. The influence of polarization functions on molecular orbital hydrogenation energies. Theor. Chim. Acta 1973, 28, 213-222.

(20) Andrae, D.; Haeussermann, U.; Dolg, M.; Stoll, H.; Preuss, H. Energy-adjusted $a b$ initio pseudopotentials for the second and third row transition elements. Theor. Chim. Acta 1990, 77, 123-141. (b) Martin, J. M. L.; Sundermann, A. Correlation consistent valence basis sets for use with the Stuttgart-Dresden-Bonn relativistic effective core potentials: the atoms $\mathrm{Ga}-\mathrm{Kr}$ and $\mathrm{In}-\mathrm{Xe}$. J. Chem. Phys. 2001, 114, 3408-3420. 
(21) Cossi, M.; Scalmani, G.; Rega, N.; Barone, V. New developments in the polarizable continuum model for quantum mechanical and classical calculations on molecules in solution. J. Chem. Phys. 2002, 117, 43-54.

(22) Scalmani, G.; Frisch, M. J.; Mennucci, B.; Tomasi, J.; Cammi, R.; Barone, V. Substitution and chemical environment effects on the absorption spectrum of indigo. J. Chem. Phys. 2006, 124, 094107.

(23) Tong, G. S. M.; Che, C.-M. Emissive or nonemissive? A theoretical analysis of the phosphorescence efficiencies of cyclometalated platinum(II) complexes. Chem. - Eur. J. 2009, 15, 72257237. 